\title{
Elafin, a Serine Elastase Inhibitor, Attenuates Post-Cardiac Transplant Coronary Arteriopathy and Reduces Myocardial Necrosis in Rabbits After Heterotopic Cardiac Transplantation
}

\author{
Bryce Cowan, Olivier Baron, Julie Crack, Claire Coulber, Gregory J. Wilson, and Marlene Rabinovitch \\ Division of Cardiovascular Research, Research Institute, The Hospital for Sick Children and Departments of Pediatrics, Pathology, \\ and Medicine, University of Toronto, Toronto, Ontario M5G 1 X8, Canada
}

\begin{abstract}
We have related experimentally induced post-cardiac transplant coronary arteriopathy to increased elastolytic activity, IL-1 $\beta$, fibronectin-mediated inflammatory and smooth muscle cell (SMC) migration, and SMC proliferation. Since our in vitro studies show that a serine elastase releases SMC mitogens and facilitates IL-1 $\beta$ induction of fibronectin, we hypothesized that administration in vivo of the specific serine elastase inhibitor, elafin, would decrease the post-cardiac transplant coronary arteriopathy. Cholesterol-fed rabbits underwent a heterotopic cardiac transplant without immunosuppression and received elafin $(1.79 \mathrm{mg} / \mathrm{kg}$ per $\mathrm{d}$ continuous infusion after a $9 \mathrm{mg}$ bolus, $n=6)$ or vehicle $(n=6)$. $1 \mathrm{wk}$ later, hearts were harvested for morphometric, immunohistochemical, and biochemical analyses. A $>70 \%$ decrease in the total number of coronary arteries with intimal thickening in elafin-treated compared to control donor hearts $(P<0.002)$ was associated with reduced vascular elastolytic activity judged by fewer breaks in the internal elastic lamina $(P<0.03)$, less accumulation of immunoreactive fibronectin $(P<0.02)$, and reduced cell proliferation quantified by proliferating cell nuclear antigen $(P<0.0001)$. Despite myocardial lymphocytic infiltration, wet weight of elafin-treated donor hearts was reduced by $50 \%$ compared to untreated controls $(P<0.002)$ and associated with relative preservation of myocyte integrity, instead of extensive myocardial necrosis $(P<0.004)$. This protective effect correlated with decreased myocardial elastolytic activity $(P<$ $0.0001)$ and inflammatory cell proliferation $(P<0.0001)$ and with an elafin-inhibitable elastase in lymphocytes. Serine elastase activity thus appears an important therapeutic target for post-cardiac transplant coronary arteriopathy and myocardial necrosis induced by rejection. (J. Clin. Invest. 1996. 97:2452-2468.) Key words: vascular disease • extracellular matrix • inflammation • cardiac rejection • fibronectin
\end{abstract}

This work was presented in part as an abstract at the American Heart Association Scientific Sessions, 13-16 November 1995 in Anaheim, CA and published in abstract form (1995. Circulation. 92:I-244-I245).

Address correspondence to Marlene Rabinovitch, M.D., Division of Cardiovascular Research, The Hospital for Sick Children, 555 University Avenue, Toronto, Ontario, M5G 1X8, Canada. Phone: 416813-5918; FAX: 416-813-7480.

Received for publication 27 December 1995 and accepted in revised form 11 March 1996.

J. Clin. Invest.

(C) The American Society for Clinical Investigation, Inc.

0021-9738/96/06/2452/17 \$2.00

Volume 97, Number 11, June 1996, 2452-2468

\section{Introduction}

The development of allograft coronary arteriopathy and its sequelae remains a major complication in the long-term survival of the cardiac transplant recipient (1-3). Intravascular ultrasound studies indicate that the prevalence of graft arteriopathy is $>50 \%$ by the fifth post-operative yr (for review see reference 4). While a number of mechanisms may contribute to the pathogenesis of progressive coronary artery neointimal thickening (4-8), an immune-mediated event is certainly involved, as lesions only occur on engrafted vessels with sparing of the host's native arteries (5). This pathogenic process involves endothelial activation, inflammatory cell recruitment, and release of soluble factors, i.e., cytokines and growth factors, that stimulate smooth muscle cell (SMC) $)^{1}$ migration, proliferation, and deposition of newly formed extracellular matrix (9-12). The soluble factors also modulate the functional status of circulating immune cells $(13,14)$. These events culminate in extensive intimal thickening characterized by diffuse concentric lesions (15).

Increased elastolytic activity is also a key feature of the coronary arteriopathy, as judged morphologically by breaks in the internal elastic lamina (IEL) $(4,16)$ and biochemically in coronary arteries after heterotopic heart transplant in piglets (17). Although contributing sources of elastolytic activity in the vascular allograft remain to be determined, primary candidates are elastases released by trafficking inflammatory cells and endogenous elastases released by vascular SMCs. The presence of allogenic $\mathrm{T}$ lymphocytes and macrophages has been documented in the coronary vasculature $(12,18-21)$ and the rejecting myocardium after cardiac transplantation (22-24). These inflammatory cells contain matrix metalloproteinases (25-29) and an elastase indistinguishable from human neutrophil elastase (25, 30-32). Recent studies have also shown that vascular SMCs can produce an endogenous elastase (33) that is induced by serum and endothelial factors (34). Cytokine stimulation of human vascular SMCs produce a complement of matrix metalloproteinases capable of degrading various matrix macromolecules, including elastin (35). IL-1 $\beta$ has also been shown to induce elastase production and activity in fibroblasts (36).

Elastases and other proteolytic enzymes are also known to regulate growth factor and cytokine activity and may, in this way, be involved in the development of neointimal lesions. They have been shown to release or activate growth factors, such as basic fibroblast growth factor (37-39) and TGF- $\beta$ (40$42)$, which are stored in the extracellular matrix. Elastases also process growth factors, such as TGF- $\alpha$, at cell surfaces $(43,44)$.

1. Abbreviations used in this paper: IEL, internal elastic lamina; IT, intimal thickening; PCNA, proliferating cell nuclear antigen; SMC, smooth muscle cell. 
IL-1 $\beta$ processing at inflammatory sites is also believed to be mediated by elastase (45) and increased elastolytic activity may be responsible for the activation of other cytokines, such as TNF- $\alpha$ (46) and IL-8 (47). Elastases produce chemotactic peptides $(29,48,49)$, which, in concert with fibronectin (50), could influence both lymphocyte transendothelial migration and SMC migration into the subendothelium.

We have previously demonstrated in vivo, using a piglet heterotopic cardiac transplant model of accelerated allograft arteriopathy, that a donor coronary artery immune-inflammatory response was associated with an increase in the expression of IL-1 $\beta$ and fibronectin (19) and in the activity of a $23-\mathrm{kD}$ serine elastase (17). Through in vitro studies we confirmed that increased production of endothelial and SMC fibronectin was reciprocally coinduced by increased levels of endogenous IL-1 $\beta(10,11)$ and TNF- $\alpha(51)$. We demonstrated the functional significance of this feature using a rabbit heterotopic cardiac transplant model in which cytokine blockade, by TNF- $\alpha$ soluble receptor (TNF- $\alpha \mathrm{sr}$ ), significantly decreased both the incidence and severity of allograft arteriopathy (18). This was associated with a reduction in both fibronectin expression and in the immune-inflammatory response $(18,52)$. We also demonstrated that blocking the integrin $\alpha_{4} \beta_{1}$ (very late antigen-4) on T lymphocytes and SMCs using peptide encoding sequences in the connecting segment (CS)-1 region of fibronectin, also reduced the incidence and severity of allograft arteriopathy (12).

Our recent in vitro studies support a cooperative interaction between coronary artery elastase and IL- $1 \beta$-induced fibronectin synthesis. Elastin peptides in the form of k-elastin can upregulate fibronectin synthesis in cultured coronary artery SMC (52a), and the serine proteinase inhibitor, alpha-1 antitrypsin, and the specific serine elastase inhibitor, elafin (53-55), reduce elastin peptide production and prevent IL-1 $\beta$ induction of fibronectin (56). The mechanism appears to be associated with the ability of elastin peptides to facilitate binding of IL-1 $\beta$ to its receptor on SMC surfaces (52a).

We therefore investigated, in rabbits after heterotopic cardiac transplant, whether inhibition of elastase in coronary arteries may prevent or reduce the coronary arteriopathy by limiting the release of mitogens and the cytokine-mediated induction of fibronectin. We administered a recombinant form of human elafin, a naturally occurring, highly specific elastase inhibitor $(55,57-59)$, since we had previously documented its effectiveness in coronary artery tissue, in vitro (17). A marked reduction in the number of allograft coronary artery intimal lesions was observed, as well as a decrease in the severity of the intimal thickening comparing elafin-treated animals to saline controls. The decreased neointimal formation was associated with a reduction in vascular elastolytic activity judged by morphometric ultrastructural analysis, fibronectin expression by semiquantitative immunohistochemistry, and cell proliferation by proliferating cell nuclear antigen (PCNA) positive cells. Whereas our previous studies, with the TNF- $\alpha$ sr or the CS- 1 peptide, produced a similar reduction in the coronary arteriopathy, elafin appeared to exert an additional protective effect against myocardial rejection necrosis in the absence of immunosuppressive therapy. This was associated with a reduction in myocardial elastolytic activity and inflammatory cell proliferation. Thus, our observations suggest a novel adjunctive therapeutic approach in which inhibition of elevated levels of elastolytic activity in cardiac allografts may be used to prevent the devel- opment of graft arteriopathy and reduce myocardial necrosis after cardiac transplantation.

\section{Methods}

Experimental animal model. The rabbit heterotopic cardiac transplant model has been previously described in detail $(18,51,60)$ and was approved by the Animal Care Committee of The Hospital for Sick Children, Toronto, CN. Briefly, outbred female New Zealand White rabbits (Charles River Laboratories, Saint Laurent, CN), weighing between 3.5 and $4.0 \mathrm{~kg}$, were unselected to favor HLA mismatch. Host rabbits were serum Pasturella free. Both host and donor rabbits were fed a $0.5 \%$ cholesterol diet (Purina 5321; Research Diets Inc., New Brunswick, NJ) for $4 \mathrm{~d}$ preoperatively, and the host was retained on the diet for the duration of the experimental period. Dietary cholesterol supplement has proven to be useful in accelerating the process of allograft arteriopathy (60). A vertical skin incision was made on the recipient rabbit in the anterior aspect of the neck, allowing isolation of the right common carotid artery and the ipsilateral jugular vein. The cardiac allograft was accomplished by anastomosing the donor aorta end-to-side to the recipient's carotid artery and the donor pulmonary artery end-to-side to the recipient's external jugular vein. Total ischemic time for the donor hearts was $30 \mathrm{~min}$. Animals received standard postoperative care in compliance with guidelines formulated by the Canadian National Society for Medical Research.

Implantation of osmotic minipumps. Osmotic minipumps (Alzet 2mL1, lot 042410; Alza Corp., Palo Alto, CA) set to deliver for $1 \mathrm{wk}$ at an hourly rate of $11.27 \pm 0.5 \mu \mathrm{l} / \mathrm{h}$ were loaded with elafin or vehicle immersed in $0.9 \% \mathrm{NaCl}$ (saline) and incubated overnight at $37^{\circ} \mathrm{C}$ to prime delivery. Implantation was performed in a lateral pocket created in the neck pouch, on the contralateral side, at the time of transplantation. The superior vena cava of each animal was accessed using a silastic catheter (customized for the $2 \mathrm{~mL} 1$ pump by Dr. A. Behoric, The Hospital for Sick Children) via the left external jugular vein. The catheter was secured in the jugular vein using silastic grommets. After a 1-ml bolus infusion of elafin/saline or saline as described below, the osmopump delivery port was connected to the catheter, and the osmopump implanted into the customized left supraclavicular pocket.

Treatment groups and administration of elafin. Animals were randomized and received one of two treatments: single dose saline and saline/vehicle infusion (sal/veh) $(n=8)$ or elafin infusion (sal/elafin) $(n=6)$. The number of animals used in each analysis is given in the Table and Figure legends. Recombinant human elafin (kindly supplied by Dr. J. Fitton of Zeneca Pharmaceuticals, Macclesfield, UK) was reconstituted with $0.9 \%$ saline (vehicle) and administered as a $2.25-\mathrm{mg} / \mathrm{kg}$ bolus followed by a $1.79 \mathrm{mg} / \mathrm{kg}$ per d continuous intravenous infusion for $7 \mathrm{~d}$. The dose chosen was extrapolated to the in vivo model based on our in vitro studies and on previously unpublished results in which the initial increase in pulmonary artery elastolytic activity in the rat model of monocrotaline-induced pulmonary hypertension was significantly reduced by osmopump administration of recombinant elafin. Unfortunately, it is still technically unfeasible to obtain serum or tissue levels for elafin. No other immunosuppressive therapy was administered to the rabbits. The grafts were monitored daily by palpation and maintained for $8 \mathrm{~d}$, an end point we have previously described to be associated with myocardial rejection (impaired cardiac contractility) and development of allograft arteriopathy in this model $(12,18)$. In one control animal, due to the absence of a palpable heartbeat in the graft, the experiment was terminated on the seventh day.

Preparation of the hearts. Preparation of hearts and grading of rejection were performed as previously described $(18,51)$. Animals were killed with a $480 \mathrm{mg}$ i.v. dose of euthanol (MTC Pharmaceutical, Cambridge, $\mathrm{CN}$ ), and host and donor hearts were harvested. Hearts were quickly drained of blood and wet weight assessed using a Libror 
EB-2800 electronic balance (Shimadzu Corp., Kyoto, Japan). Apices of hearts were removed to assess elastolytic activity of the myocardium in host and donor hearts from two different saline- and elafintreated animals. Conical apical sections were isolated by a transverse cut $\sim 1 \mathrm{~cm}$ from the apex of the heart. Sections were taken from hearts before perfusion, and tissue was immediately frozen in liquid nitrogen and stored at $-70^{\circ} \mathrm{C}$.

Coronary arteries in all animals were perfused through the aorta with saline followed by mild fixation by a $2 \%$ paraformaldehyde perfusion (Sigma Chemical Co., St. Louis, MO). Due to the relatively uniform distribution of cardiac allograft arteriopathy throughout the coronary circulation $(18,51,61,62)$, hearts were sectioned transversely from the base to apex. Sections were preserved in $10 \%$ formalin (BDH Inc., Toronto, ON) for light microscopic morphometric analysis or immediately frozen in O.T.C. Compound Tissue Tek (Miles Laboratories Inc., Elkart, IN) for immunohistochemical studies.

In three donor and host hearts from each group, large intramyocardial coronary arteries (diameter range 500-950 $\mu \mathrm{m}$ ) were used for ultrastructural assessment of elastin degradation. After death, portions of the base of the heart containing coronary artery segments of the left anterior descending, the left circumflex, and the right coronary arteries, $\sim 1 \mathrm{~cm}$ in length, were removed from both host and donor hearts, trimmed, and processed as described below.

Grading of rejection. Donor heart sections were stained with hematoxylin and eosin for histological grading of rejection. Sections were graded qualitatively by G.J. Wilson, a cardiovascular pathologist, and B. Cowan, without knowledge of whether the donor hearts came from saline- or elafin-treated animals and subsequently graded quantitatively in an unblinded fashion by B. Cowan, under the direction of G.J. Wilson. To assess rejection quantitatively, three transmural sections of the left ventricular free wall were graded for each heart, with respect to necrotic and inflammatory features. The proportions of each section showing: $(a)$ acutely necrotic cardiomyocytes; $(b)$ areas of myocyte loss termed "dropout" or replacement with fibrous tissue; and (c) areas of myocyte loss filled with inflammatory cells consisting of lymphocytes, macrophages, and granulocytes, termed "infiltrative obliteration," were estimated and added together to express necrosis as a percentage of total tissue area. Inflammation was quantified as the proportion of each section showing either $(a)$ inflammatory cell infiltration, adjacent to cardiomyocytes but not obliterating them or $(b)$ infiltrative obliteration, which were esti- mated and added together to express inflammation as a percentage of total tissue area. It is noteworthy that inflammatory obliteration was represented in both the assessment of necrosis and inflammation. For each transmural section of the left ventricle, the percentages of viable cardiomyocytes, acutely necrotic myocytes, myocyte dropout and replacement, infiltrative obliteration, and inflammatory cell infiltration added to $100 \%$.

Morphological assessment by transmission electron microscopy. Morphometric ultrastructural assessment of degradation of the IEL in intramyocardial coronary arteries from host and donor hearts in saline- and elafin-treated rabbits was performed as previously described in piglets (17). Coronary artery sections fixed in $0.1 \%$ glutaraldehyde were postfixed in $1 \%$ osmium tetroxide and embedded in epon resin. Toluidine blue sections $(1 \mu \mathrm{m})$ were screened. Ultrathin sections $(60-90 \mathrm{~nm})$ were prepared on high resolution nickel grids and stained with $5 \%$ uranyl acetate and $0.4 \%$ lead citrate. The grids were examined on an electron microscope (model 201; Philips Electronic Instruments, Mahwah, NJ). At least two sections from each vessel were analyzed, and 10 photomicrographs including the IEL were taken at a magnification of 3,760. Analysis of the negatives was performed using a Photovix (Tamron Inc., Japan) film video processor attached to a computer-generated video analysis system (New Vision 10 Software; Perceptics Corp., Knoxville, TN). To assess fragmentation, regions of IEL disruption were counted, standardized to extrapolated continuous IEL length, and a mean value was calculated for each vessel. To assess loss of IEL length, lengths of lamina in equivalent viewing fields were summed, standardized to extrapolated continuous IEL length viewed, and a mean value was calculated for each vessel.

Quantitative assessment of host and donor coronary arteries by light microscopy. Three tissue sections from both host and donor hearts from six different saline- and elafin-treated rabbits were fixed in $10 \%$ Formalin, embedded in paraffin, and stained by the Movat pentachrome method. Light microscopic morphometric analysis was performed using a Zeiss microscope (Carl Zeiss, Inc., Thornwood, $\mathrm{NY})$ attached to a computer-generated video analysis system (Nu Vision Software; Perceptics, Inc.) as previously described (12). In each heart section, the diameter of each vessel was measured, and the coronary arteries were categorized as small $(\leq 100 \mu \mathrm{m}$ diameter $)$, medium $(>100 \leq 500 \mu \mathrm{m}$ diameter $)$, or large $(>500 \mu \mathrm{m}$ diameter $)$. For each heart, the number of vessels in each size category with intimal

Table I. Morphometric and Immunohistochemical Findings in Coronary Arteries of Individual Rabbits

\begin{tabular}{|c|c|c|c|c|c|c|c|c|c|}
\hline \multirow[b]{2}{*}{ Animal } & \multirow[b]{2}{*}{ Treatment } & \multicolumn{2}{|c|}{ Mean number cells/vessel } & \multirow[b]{2}{*}{$\mathrm{FN}$} & \multicolumn{3}{|c|}{$\begin{array}{l}\text { Mean number of } \\
\text { PCNA-positive cells }\end{array}$} & \multirow{2}{*}{$\begin{array}{l}\text { Number of vessels } \\
\text { with IT (\% total) }\end{array}$} & \multirow{2}{*}{$\begin{array}{r}\text { Severity of IT } \\
\text { (\% vessel area) }\end{array}$} \\
\hline & & $\mathrm{T}$ cells & Macrophages & & $\mathrm{L}$ & M & $\mathrm{s}$ & & \\
\hline 1 & Elafin & 12 & 0 & $+1-$ & 2 & 8 & 4 & $4 \%$ & $30 \%$ \\
\hline 2 & Elafin & 26 & 0 & - & 0 & 2 & 1 & $1 \%$ & $20 \%$ \\
\hline 3 & Elafin & 0 & 0 & - & 2 & 5 & 1 & $5 \%$ & $35 \%$ \\
\hline 4 & Elafin & 1 & 0 & - & NA & 4 & 2 & $1 \%$ & $30 \%$ \\
\hline 5 & Elafin & 19 & 12 & $+1-$ & 0 & 10 & 3 & $23 \%$ & $50 \%$ \\
\hline 6 & Elafin & 6 & 0 & - & 2 & 3 & 0 & $5 \%$ & $28 \%$ \\
\hline 7 & CTRL & 8 & 0 & + & 75 & 20 & 7 & $44 \%$ & $50 \%$ \\
\hline 8 & CTRL & 25 & 8 & + & NA & 17 & 1 & $98 \%$ & $53 \%$ \\
\hline 9 & CTRL & 18 & 4 & ++ & 55 & 49 & 9 & $66 \%$ & $60 \%$ \\
\hline 10 & CTRL & 5 & 4 & + & 8 & 21 & 7 & $71 \%$ & $68 \%$ \\
\hline 11 & CTRL & 12 & 0 & $+1-$ & 22 & 11 & 2 & $42 \%$ & $50 \%$ \\
\hline 12 & CTRL & 8 & 0 & + & NA & 9 & 3 & $62 \%$ & $52 \%$ \\
\hline
\end{tabular}

FN, fibronectin; IT, intimal thickening; CTRL, control (0.9\% saline); L, arteries ( $>500 \mu \mathrm{m}$ diameter); M, arteries $(>100 \leq 500 \mu \mathrm{m}$ diameter); S, arteries ( $\leq 100 \mu$ m diameter);,$-+/-,+,++,+++$, negative, minimal, little, moderately abundant, and very abundant; NA, not assessed. 
proliferation was expressed as a percentage of total vessel number. In the host hearts, 737 vessels in the control group and 1,013 in the elafin group were analyzed. In the donor hearts, 690 vessels in the control group and 1,117 in the elafin group were assessed. The severity of intimal thickening was quantitatively assessed in each affected vessel, according to a method previously described (63). The areas encompassed by the outer medial layer (ML), the IEL, and the lumen were measured, and the area of intimal thickening (IT) related to the vessel area was calculated by the formula: $I T=(I E L-$ lumen area $) /$ $(M L-$ lumen area $) \times 100$.

Analysis of immunohistochemistry. In all immunohistochemical studies, sections from host and donor hearts from six different salineand elafin-treated groups were used to analyze coronary arteries in the different size ranges, comparing vessels with and without intimal proliferation. The relative abundance of each specific antigen studied in the sections examined was graded semiquantitatively as negative $(-)$, minimal $(+/-)$, little $(+)$, more abundant $(++)$, or very abundant $(+++)$ by two of the authors independently (B. Cowan and M. Rabinovitch). The final scoring was based on the average of the individual gradings. There was complete agreement in the grading of $>87 \%$ of the cases.

The abundance of inflammatory cells studied was also examined quantitatively. The number of positive cells, per vessel, was counted, and a mean number was generated for each animal. Due to an equivalent representation of vessel sizes (small, $\leq 100 \mu \mathrm{m}$ diameter; medium, $>100 \leq 500 \mu \mathrm{m}$ diameter; large, $>500 \mu \mathrm{m}$ diameter) in each group but not within each animal, values were generated from the total number of vessels for statistical analyses, but mean values for each animal are given in Table I. The number of inflammatory cells in the myocardium was evaluated in eight randomly selected fields $\left(290-\mu \mathrm{m}^{2}\right.$ fields at an original magnification of 40) and expressed as the mean number of positive cells per field, in each animal. Proliferation of cells was quantified using sections stained for PCNA. The number of positive cells, per vessel, was counted, and a mean number was generated for each vessel size range (small, $\leq 100 \mu \mathrm{m}$ diameter; medium, $>100 \leq 500 \mu \mathrm{m}$ diameter; large, $>500 \mu \mathrm{m}$ diameter). Proliferation of cells in the myocardial infiltrate was expressed in each animal as a ratio of positive cells over total number of cells counted in eight randomly selected fields $\left(290-\mu \mathrm{m}^{2}\right.$ fields at an original magnification of 40). Values in the donor were corrected for the mean number of positive cells, which had been calculated from an equivalent number of fields from the respective host heart.

Immunostaining for fibronectin. Identification of fibronectin was performed with a monoclonal $\mathrm{IgG}_{1}$ anti-human cellular fibronectin antibody (Chemicon International Inc., Temecula, CA). Frozen sections were air dried for $2 \mathrm{~h}$, fixed in acetone for $20 \mathrm{~min}$, and rinsed with PBS $/ 0.1 \%$ BSA (Boehringer-Mannheim, Mannheim, Germany) (PBS/BSA). Endogenous peroxidase activity was blocked by immersing the sections in PBS/BSA with $1 \%$ hydrogen peroxide $\left(\mathrm{H}_{2} \mathrm{O}_{2}\right)$ (BDH Inc.) for $30 \mathrm{~min}$. After a nonspecific blocking step using 5\% normal horse serum (Vectastain ABC System; Vector Laboratories, Inc. Burlingame, $\mathrm{CA}$ ), we incubated the sections in primary antibody (1:50 dilution) overnight at $4^{\circ} \mathrm{C}$, and antibody binding was visualized using the Vectastain ABC System. Control sections were treated with normal mouse isotypic IgG (Dako Corp., Carpinteria, CA).

Immunostaining for cell proliferation. The presence of proliferating cells within the vessel wall was assessed in deparaffinized sections using an mAb to PCNA (Dako Corp.). After a brief nuclease digestion, endogenous peroxidase activity was blocked by immersing the sections in methanol with $1 \% \mathrm{H}_{2} \mathrm{O}_{2}$ for 30 min. Sections were incubated in primary antibody $(1: 100)$ for $4 \mathrm{~h}$ at $25^{\circ} \mathrm{C}$, and antibody binding was visualized using the PCNA Kit (Dako Corp.). Control sections were treated with normal mouse isotypic IgG (Dako Corp.). To assess whether some of the PCNA-positive cells were likely to represent SMC, immunostaining of deparaffinized sections using an antibody to smooth muscle alpha actin (Dako Corp.) was also carried out. Sections were treated as described for PCNA staining above. Sections were incubated in primary antibody $(1: 100)$ overnight at $4^{\circ} \mathrm{C}$, and antibody binding was visualized using $3,3^{\prime}$-diaminobenzidine (Sigma Chemical Co.). Control sections were treated with normal mouse isotypic IgG (Dako Corp.).

Characterization of inflammatory cells. The presence of an inflammatory reaction and inflammatory cells adherent to the coronary artery endothelium and within the vessel wall was determined using $\mathrm{mAbs}$ to rabbit $\mathrm{T}$ cells (a gift from Dr. Peter Libby, Brigham and Woman's Hospital, Boston, MA) and macrophages (RAM 11; Dako Corp., Carpinteria, CA). Immunoperoxidase staining was performed using frozen sections prepared as described above. The specimens were immersed for $30 \mathrm{~min}$ in $1 \% \mathrm{H}_{2} \mathrm{O}_{2}$ solution in methanol to block exogenous peroxidase activity, and, after a nonspecific blocking step in 5\% normal horse serum (Vectastain ABC System), the sections were incubated overnight with primary antibody (1:10 dilution) at $4^{\circ} \mathrm{C}$. Antibody binding was visualized using the Vectastain ABC System and developed with 3,3'-diaminobenzidine (DAB) (Sigma Chemical Co.). Control sections were treated with normal mouse isotypic $\mathrm{IgG}$ (Dako Corp.).

Assessment of myocardial elastolytic activity. The procedure for measuring elastolytic activity was previously described (64) and modified by our group (65). Tissues were minced and then homogenized in $0.9 \%$ saline using a Polytron (Brinkmen Homogenizer; Brinkman Instruments, Westbury, NY). The homogenate was centrifuged at 2,800 $\mathrm{g}$ for $30 \mathrm{~min}$ at $4^{\circ} \mathrm{C}$ and the pellet was extracted twice for $18 \mathrm{~h}$ in $4 \mathrm{ml}$ of $0.5 \mathrm{~mol} /$ liter sodium acetate buffer, $\mathrm{pH}$ 4.0. The extracts were pooled and dialyzed against distilled water at $4^{\circ} \mathrm{C}$ overnight and lyophilized. The lyophilized powder was reconstituted in $2 \mathrm{ml}$ of $60 \%$ saturated ammonium sulfate solution, shaken gently for $1 \mathrm{~h}$ at room temperature, placed at $4^{\circ} \mathrm{C}$ overnight to precipitate the proteins, and then centrifuged for $10 \mathrm{~min}$ at $8,160 \mathrm{~g}$ at $4^{\circ} \mathrm{C}$. All solutions contained 2 $\mathrm{mM} /$ liter methylamine to inhibit $\alpha_{2}$-macroglobulin. The pellet was resuspended in $300 \mu \mathrm{l}$ of Tris Assay Buffer $(50 \mathrm{mM}$ Tris- $\mathrm{HCl}, 150 \mathrm{mM}$ $\mathrm{NaCl}, 10 \mathrm{mM} \mathrm{CaCl} \cdot 2 \mathrm{H}_{2} \mathrm{O}, 0.02 \%$ Brij, $\left.0.02 \% \mathrm{NaN}_{3}, \mathrm{pH} 8.0\right)$. Triplicate samples of $70 \mu \mathrm{l}$ were incubated with $20 \mu \mathrm{l}(200 \mu \mathrm{g})\left[{ }^{3} \mathrm{H}\right]$ elastin substrate (produced as described below) and additional Tris Assay Buffer was added to correct the total vol to $220 \mu$ l. Samples were incubated for $18 \mathrm{~h}$ at $37^{\circ} \mathrm{C}$ and centrifuged at $8,160 \mathrm{~g}$ for $4 \mathrm{~min} .100-\mu \mathrm{l}$ aliquots of supernatant were added to $4 \mathrm{ml}$ of aqueous counting scintillation fluid and counted for $2 \mathrm{~min}$ in a 1219 Rackbeta (LKB Wallac, San Francisco, CA) scintillation counter. In each assay, elastolytic activity was calculated using a standard curve generated with human leukocyte elastase (0.075-5.0 ng) (Elastin Products Company, St. Louis, $\mathrm{MO}$ [sp act $875 \mathrm{U} / \mathrm{mg}$ protein]), and the mean value of triplicate samples was used in the calculation of elastolytic activity.

Production of insoluble $\left[{ }^{3} \mathrm{H}\right]$ elastin. Purified insoluble elastin from bovine nuchal ligament (Elastin Products Company, Owensville, MO) was radiolabeled as previously described using $\left[{ }^{3} \mathrm{H}\right] \mathrm{NaBH}_{4}(\mathrm{New}$ England Nuclear, Boston, MA) (66). $\left[{ }^{3} \mathrm{H}\right]$ elastin was reconstituted at 16 $\mathrm{mg}$ elastin/ml (sp act was $\sim 2,000 \mathrm{cpm} / \mu \mathrm{g}$ elastin) in Tris Assay Buffer and stored at $-70^{\circ} \mathrm{C}$ before performing the assay. Before use, $\left[{ }^{3} \mathrm{H}\right]$ elastin was boiled and washed with Tris Assay Buffer until the background counts became less than $100 \mathrm{cpm} / 100 \mu \mathrm{l}$ supernatant. The $\left[{ }^{3} \mathrm{H}\right]$ elastin suspension was then diluted to $100,000 \mathrm{cpm} / 20 \mu \mathrm{l}$ (= $200 \mu \mathrm{g}$ insoluble elastin).

Preparation of rabbit lymphocytes. Heparinized rabbit peripheral blood was obtained from peripheral ear arteries of two different 4-6 $\mathrm{kg}$ Charles River New Zealand White female rabbits, as well as from one transplant control animal. The PBMCs were separated by FicollPaque (Pharmacia Fine Chemicals, Uppsala, Sweden) density gradient centrifugation as previously described $(50,67)$. The mononuclear cells were washed twice in HBSS (Sigma Chemical co.), resuspended in M199 culture medium supplemented with $25 \mathrm{mM}$ Hepes buffer, $2 \mathrm{mM}$ glutamine, $1 \%$ antibiotics/antimycotics (Gibco, Burlington, $\mathrm{CN}$ ), and $10 \%$ FBS (Intergen Co., Purchase, NY), and counted in a Coulter cell counter (Model ZF; Coulter Electronics, Hialeah, FL). Monocytes were excluded by the adherence method in which PBMCs are incubated on $150 \mathrm{~cm}^{3}$ tissue culture flasks at a concentration of $2 \times 10^{6} / \mathrm{ml}$ for $1 \mathrm{~h}$ at $37^{\circ} \mathrm{C}$. This procedure yields a suspension of lymphocytes 
$80-90 \%$ pure (68). Nonadherent cells were removed, pooled, resuspended, and extensively washed in RPMI 1640 medium before seeding in 16-mm tissue culture wells for assessment of elastolytic activity. The proportion of lymphocytes in our peripheral rabbit white blood cell (WBC) fraction was $45-50 \%$, whereas monocytes comprise $\sim 4$ $9 \%$ of the peripheral WBC fraction (assessed by the clinical hematology laboratory at The Hospital for Sick Children). It is unlikely that monocyte contamination would be largely responsible for the levels of elastolytic activity observed in the peripheral lymphocyte fraction isolated, as monocytes and lymphocytes produced similar levels of enzyme activity (data not shown).

Lymphocyte elastolytic activity. Elastin degradation by lymphocytes was measured as solubilization of $\left[{ }^{3} \mathrm{H}\right]$ elastin $(29,69) .\left[{ }^{3} \mathrm{H}\right]$ elastin was dried on the bottom of wells of 16-mm multiwell tissue culture plates (Corning Glass Works, Corning, NY). Plates were prepared as follows: $\left[{ }^{3} \mathrm{H}\right]$ elastin suspension was thawed and washed extensively in deionized water with $0.02 \%$ Brij until the background counts were below $100 \mathrm{cpm}$. After regulating the suspension to $\sim 300,000 \mathrm{cpm} / 250 \mu \mathrm{l}$, $250 \mu \mathrm{l}$ of suspension was placed in each well and allowed to air dry overnight under ultraviolet light in a tissue culture hood. Weakly adherent elastin was washed from the wells with warm RPMI 1640 medium (Gibco) before cell seeding. Rabbit peripheral blood T lymphocytes, suspended in RPMI 1640 medium fortified with 10\% FBS and plated at $5 \times 10^{5}$ cells $/ \mathrm{ml}$. Cells were allowed to react with the substrate for $18-24 \mathrm{~h}$ at $37^{\circ} \mathrm{C}$. After the culture period, $600 \mu \mathrm{l}$ of culture medium was harvested, transferred to an Eppendorf vial, and microcentrifuged at $8,160 \mathrm{~g}$ for $4 \mathrm{~min}$. The radioactivity of the supernatant $(500 \mu \mathrm{l})$ was assayed for ${ }^{3} \mathrm{H}$ by liquid scintillation spectrometry (as above). To control for nonenzymatic degradation of the elastin substrate, elastin degradation was corrected for media blanks. Blanks were $<0.1 \%$ of the cpm bound to each well. Elastin degradation was corrected for $5 \times 10^{5}$ cells and then expressed as micrograms of elastin solubilized. Experimental wells did not release $>1 \%$ of the total radioactivity applied. Assays were performed in triplicate.

Statistical analysis. Data are expressed as mean \pm SEM in Results and the Figure legends. All analyses were performed using ANOVA with post hoc paired subgroup testing by Fisher's analysis and $P$ value corrected for multiple comparisons. When only two groups were compared, e.g., numbers of inflammatory cells/myocardial field in donor elafin versus donor saline, the Fisher's analysis was also used. The correlation among categorical variables (i.e., fibronectin immunohistochemistry) was analyzed using Fisher's exact test. In assessments of fibronectin, sections were considered positive if $\geq+$ in the two groups (control and elafin-treated). In comparing myocardial rejection and inflammation, the mean percentage from the three sections for each animal was used and comparison was made between control and elafin-treated groups by the Mann-Whitney rank sum test. In all analyses differences were considered statistically significant at $P \leq 0.05$.

\section{Results}

Morphological assessment by transmission electron microscopy. Using a computer-generated video analysis system to analyze SEM negatives of coronary artery cross-sections, we observed both qualitatively and quantitatively that, unlike the largely intact IEL of host coronary arteries, the IEL of donor coronary arteries of control (saline)-treated rabbit hearts was greatly fragmented (Fig. 1). When degradation of the IEL was assessed by the number of disruptions per $100 \mu \mathrm{m}$, the IEL of donor vessels in the control group showed approximately a twofold increase in the number of disruptions per $100 \mu \mathrm{m}$ when compared to host values $(8 \pm 1 / 100 \mu \mathrm{m}$ vs. $3 \pm 1 / 100 \mu \mathrm{m})$ ( $n=3$ per group) $(P<0.03)$. In contrast, donor arteries in the elafin-treated group showed no increase in the number of disruptions per $100 \mu \mathrm{m}$ when compared to host values.

When degradation of the IEL was assessed by the length of

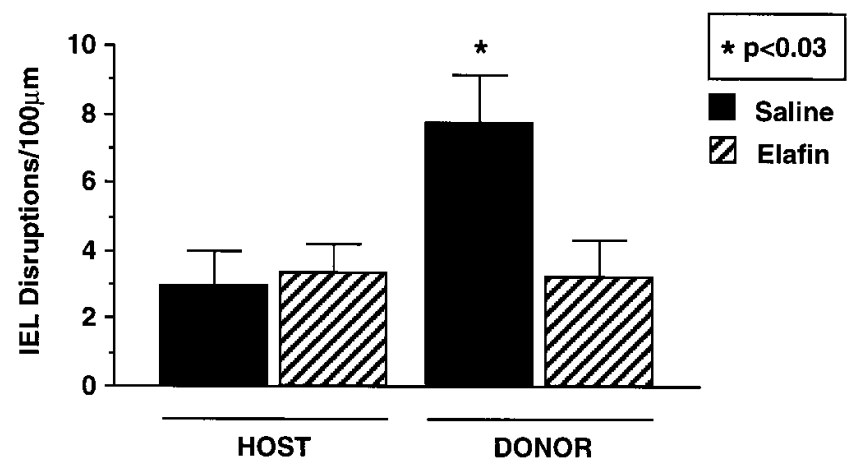

Figure 1. Effect of elafin administration on IEL degradation in host and donor coronary arteries from rabbit hearts after heterotopic cardiac transplantation. Number of disruptions per $100 \mu \mathrm{m}$ of IEL length in host and donor coronary artery from control and elafintreated animals were compared in three randomly selected rabbits from each treatment group. Values for disruptions of IEL increased in donor control arteries relative to all other groups $(* P<0.03$ for all comparisons).

intact IEL remaining per $100 \mu \mathrm{m}$ of coronary artery length, the IEL of donor vessels in the control group showed a $39 \%$ loss in the length of intact IEL per $100 \mu \mathrm{m}$ of coronary artery length when compared to host values $(P<0.0006)$. In contrast, donor vessels in the elafin-treated group did not show a significant decrease in the length of intact IEL per $100 \mu \mathrm{m}$ when compared to host values. Representative photomicrographs of the IEL from coronary arteries in the host, donor, and donor elafintreated animals are shown in Fig. 2, $A, B$, and $C$, respectively.

Morphometric analyses of host and donor coronary arteries. Using light microscopic morphometric analysis applied to the Movat pentachrome-stained histologic sections, we observed no large coronary arteries ( $>500 \mu \mathrm{m}$ diameter) with intimal thickening in host hearts from control (vehicle) and elafintreated groups $(n=6)$ (Fig. 3$)$. In donor hearts from the control group, however, $50 \pm 12 \%$ SEM of the large vessels had intimal thickening, whereas in the elafin-treated group only $21 \pm 8 \%$ SEM were affected $(P<0.005)$. Medium- $(>100 \leq$ $500 \mu \mathrm{m}$ diameter) and small-sized $(\leq 100 \mu \mathrm{m}$ diameter $)$ coronary arteries comprised numerically the overwhelming majority $(>90 \%)$ of vessels available for analysis. Those from host hearts of control and elafin-treated groups displayed minimal intimal thickening ranging from $4 \pm 2 \%$ SEM in medium-sized vessels from elafin-treated animals to $1 \pm 0.4 \%$ SEM in the small sized vessels of host hearts from control animals. In contrast, most of the medium and small sized vessels from donor hearts of the control group displayed intimal thickening ( $78 \pm 3$ and $54 \pm 2 \%$ SEM, respectively). In the elafin-treated group only $18 \pm 3$ and $6 \pm 1 \%$ SEM vessels of comparable size were affected $(P<0.0001)$. Taken together, the presence of elafin resulted in a 58,77 , and $89 \%$ reduction in the incidence of intimal lesions in large-, medium-, and small-sized donor coronary arteries, respectively. Average values for the total number of affected vessels in each animal of both donor groups is included in Table I.

The severity of the lesions, judged in affected vessels by the area of intimal thickening as a portion of total vessel area, was similar in medium and small host coronary arteries from both control and elafin-treated groups (range: $23 \pm 3-33 \pm 4 \%$ SEM) $(n=6)$ (Fig. 4). Intimal thickening in large vessels from donor 

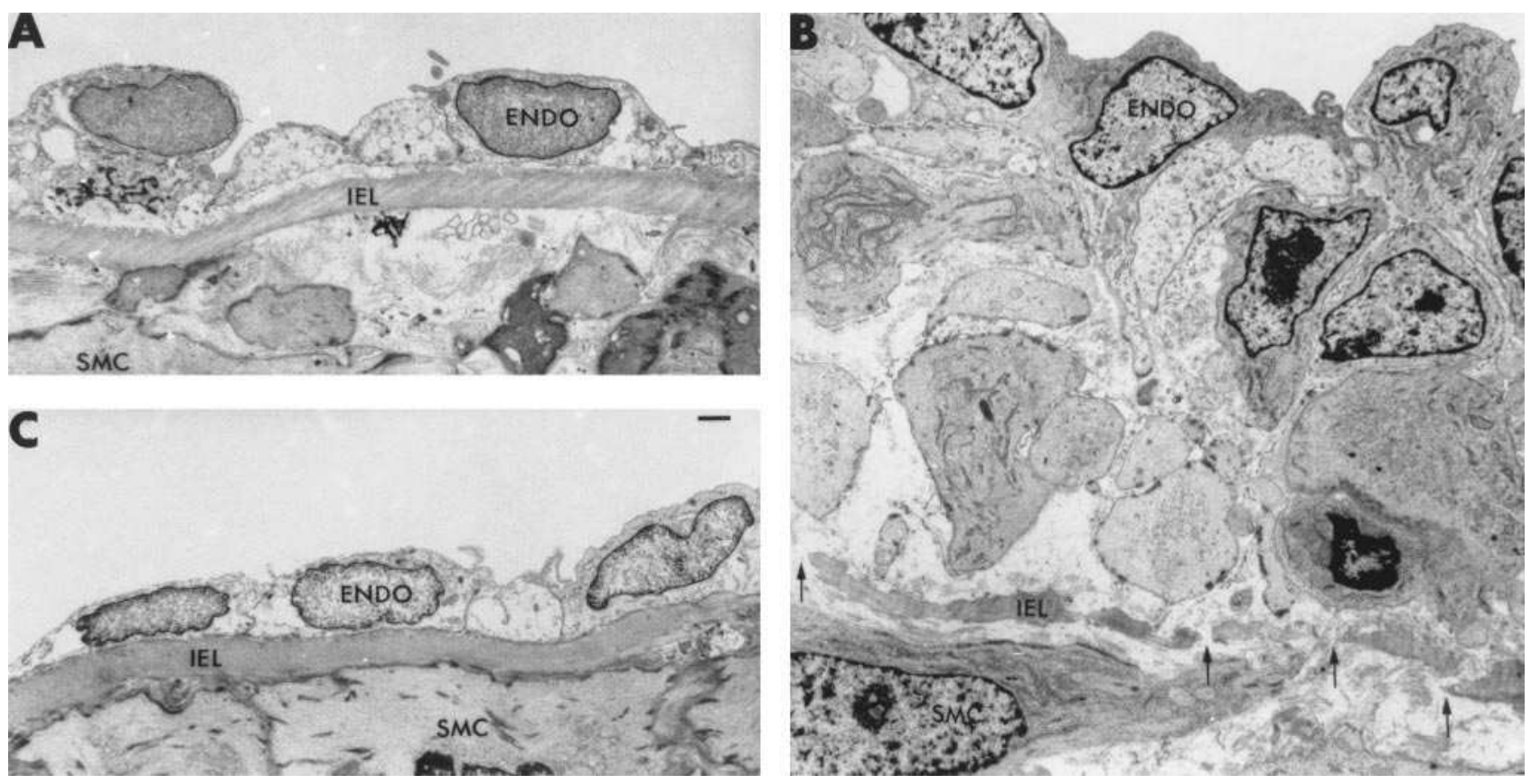
Figure 2. Representative electron photomicrographs of host $(A)$ donor $(B)$ and elafin-treated donor $(C)$ coronary arteries. No disruptions are
seen in the IEL of host coronary arteries, whereas the IEL of donor coronary arteries are tortuous and exhibit multiple disruptions (arrows). In contrast, donor arteries from animals receiving elafin treatment structurally resemble the IEL of host arteries. ENDO, endothelial cell; SMC, smooth muscle cell; $I E L$, internal elastic lamina. $\times 3,760$; scale bar $=1 \mu \mathrm{m}$.

control animals was $29 \pm 4 \%$ SEM of total vessel area. In the elafin-treated group, large vessel intimal thickening was reduced by $50 \%$, but this difference was not reflected in statistical significance due to the small number of compromised vessels in this size range $(n=13$ in total). Intimal thickening in medium and small donor arteries from control animals displayed a onefold increase in severity above host levels. In the elafin-treated group, intimal thickening in these vessels was reduced by 28 and $18 \%$, respectively ( $P<0.0001$ for both). However, lesions in medium and small donor arteries of elafintreated animals remained significantly larger than their host

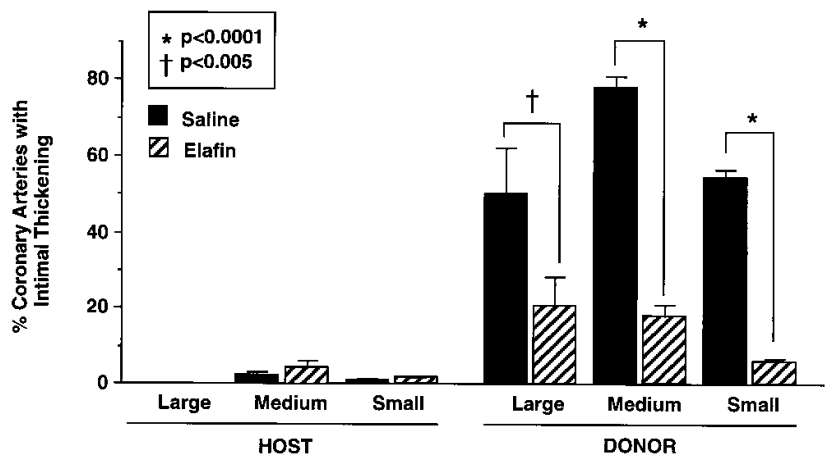

Figure 3. Effect of recombinant human elafin treatment on the number of coronary arteries with intimal lesions in both host and donor hearts. Intimal thickening was observed in large $(>500 \mu \mathrm{m}$ diameter), medium $(>100 \leq 500 \mu \mathrm{m}$ diameter $)$, and small $(\leq 100 \mu \mathrm{m} \mathrm{di}-$ ameter) coronary arteries. The number of vessels in the elafin-treated group were significantly reduced compared to the control group $\left({ }^{\dagger} P<0.005\right.$ for large coronary artery and $* P<0.0001$ for medium and small coronary artery, respectively). In host coronary arteries, no differences were observed in groups for large-, medium-, and smallsize vessels. saline and elafin counterparts $(P<0.02$ and $P<0.002$, respectively). Average values for severity of intimal thickening in each animal of both donor groups is included in Table I. Representative examples of coronary arteries in the host, donor, and donor elafin-treated animals are shown in Fig. 5, $A, B$, and $C$, respectively.

Assessment of fibronectin accumulation and the coronary arteries. Minimal immunostaining for cellular fibronectin was observed in host arteries of control animals (Fig. $6 \mathrm{~A}$ ). In contrast, donor coronary arteries of control animals showed moderate to abundant $(+$ to ++$)$ fibronectin in five of six animals (Fig. $6 \mathrm{~B}$, Table I), whereas coronary arteries of elafin-treated

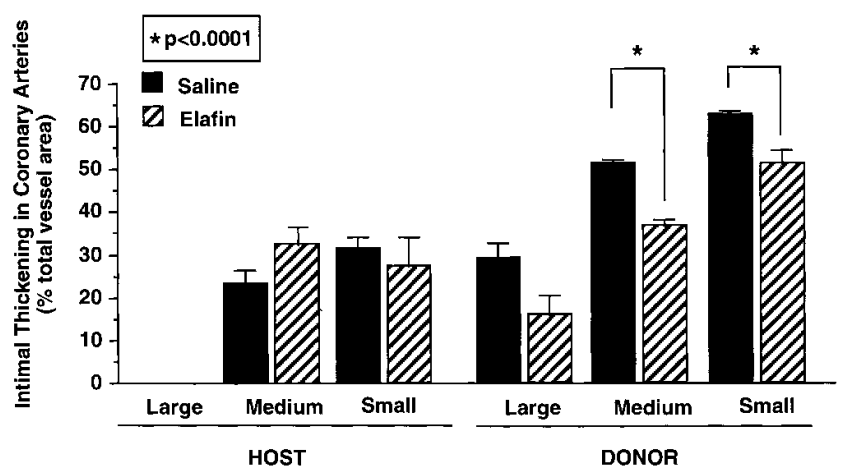

Figure 4. Effect of recombinant human elafin treatment on the severity of coronary artery intimal lesions in affected arteries as assessed by intimal thickening (as a percentage of total vessel area) related to vessel size in both host and donor hearts. There was a significant reduction in the severity of intimal thickening in both medium- $(>100$ $\leq 500 \mu \mathrm{m}$ diameter) and small- ( $\leq 100 \mu \mathrm{m}$ diameter) size vessels of the elafin-treated group when compared with the control donor group $(* P<0.0001)$. 

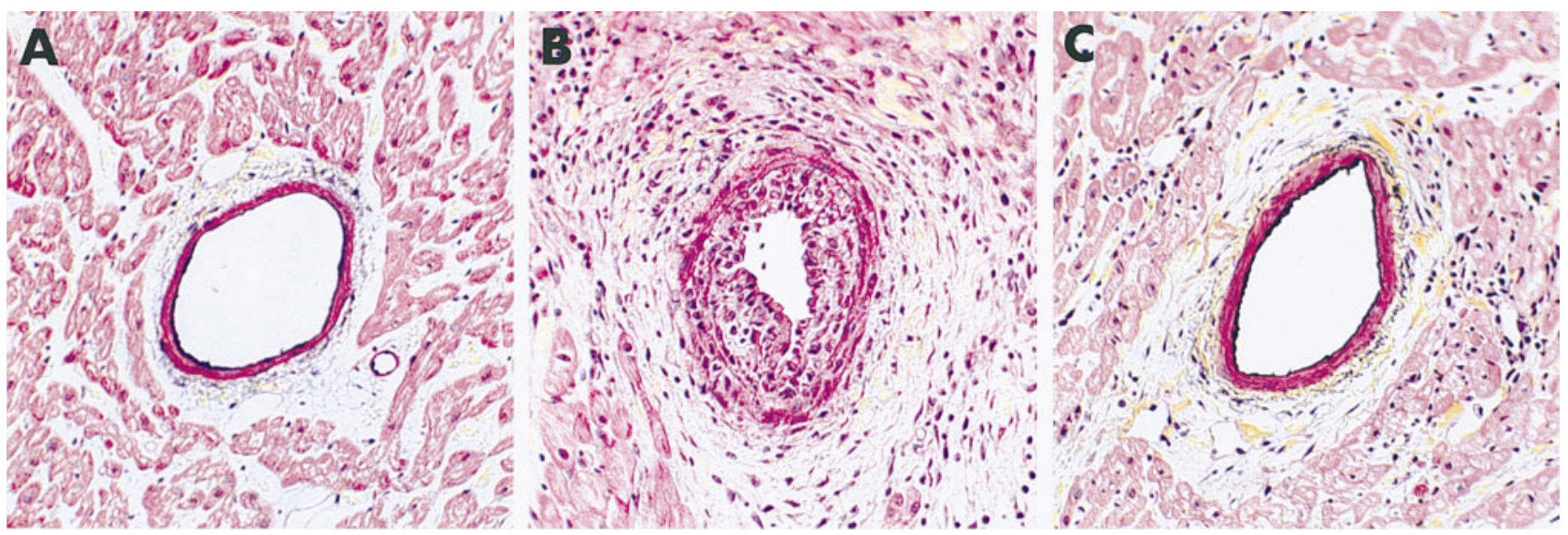

Figure 5. Representative photomicrographs of Movat pentachrome staining of coronary arteries in the host control, donor control, and elafintreated donor groups. The normal appearing host vessel $(A)$ contrasts with the affected donor vessel $(B)$ showing a concentric intimal lesion in the control group and a more normal appearing artery in the elafin-treated donor group $(C)$. All vessels are in the medium- $(>100 \leq 500 \mu \mathrm{m}$ diameter) size range. Original magnification 200.

rabbits showed negative to minimal immunostaining $(-$ to $+/-)$ (Fig. $6 C)(P<0.02)$. Fibronectin expression in the donor arteries of the control group occurred throughout the media and intima, whereas fibronectin immunostaining in the donor coro- nary arteries of elafin-treated animals was usually localized to the intima. The animal expressing the least intense fibronectin staining in the control group possessed both the least number of compromised vessels and severity of intimal thickening

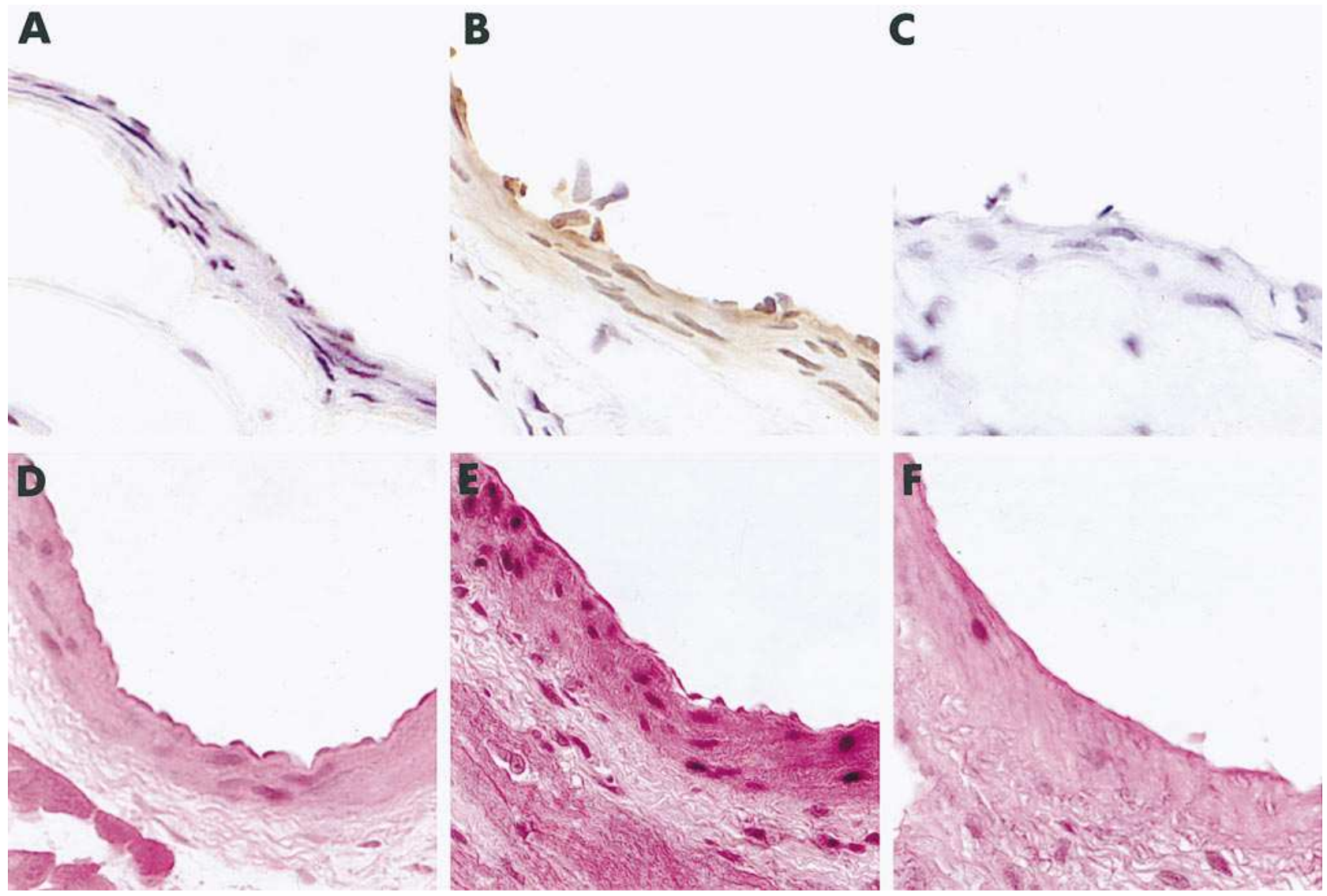

Figure 6. Representative photomicrograph of immunoperoxidase staining for cellular fibronectin $(A-C)$ and proliferating cell nuclear antigen $(D-F)$ in host and donor coronary arteries from both control and elafin-treated groups. The accumulation of cellular fibronectin was minimal in host vessels $(A)$. Donor coronary arteries from the control group showed abundant accumulation of fibronectin $(B)$, whereas, donor coronaries of elafin-treated rabbits showed a similar level of fibronectin accumulation (negative to minimal) as seen in host vessels $(C)$ ). A minimal level of PCNA staining was also seen in host vessels $(D)$. PCNA staining was notably increased in the media and adventitia of donor coronary arteries of control animals $(E)$ and reduced below host levels in donor coronary arteries of elafin-treated rabbits $(F)$. Original magnification 600. 


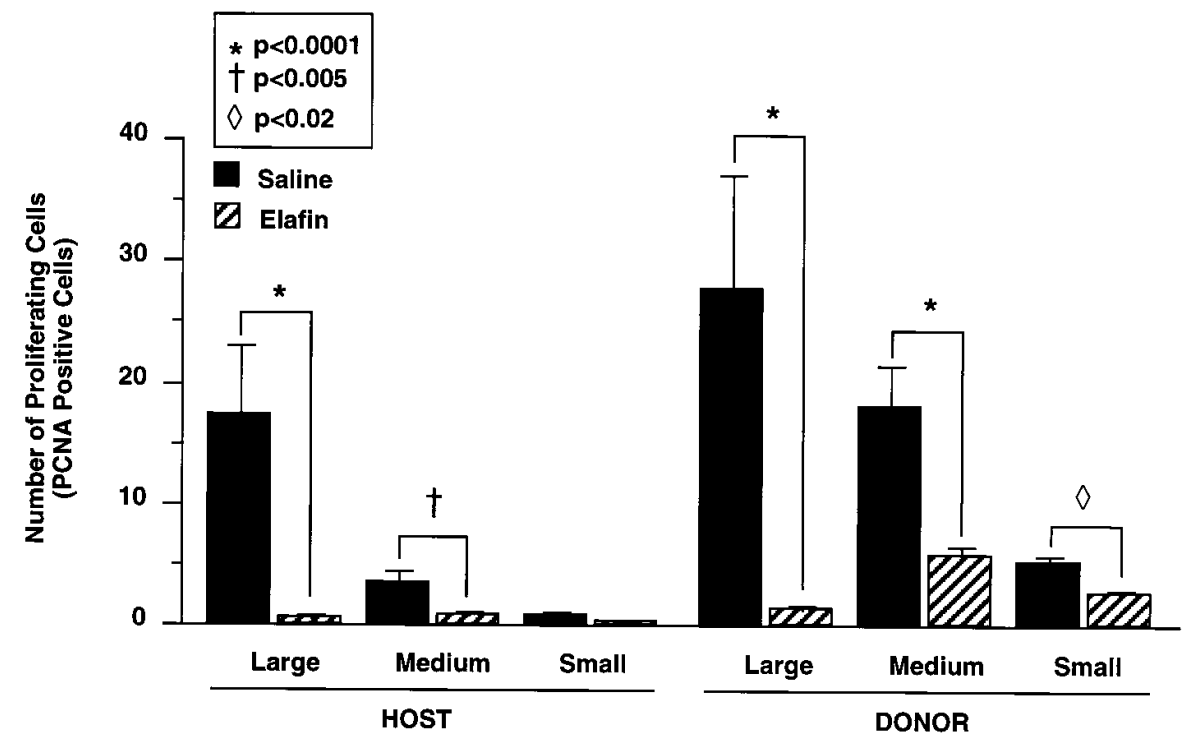

Figure 7. Effect of recombinant human elafin treatment on cellular proliferation in coronary arteries as assessed by positive staining for PCNA in host and donor hearts from control and elafin-treated animals. There was a greater than threefold increase in the number of proliferating cells in both medium- $(>100 \leq 500 \mu \mathrm{m}$ diameter) and small- $(\leq 100 \mu \mathrm{m}$ diameter) size vessels of the donor control group relative to the host $(P<0.0001$ and $P<0.0005$, respectively, not indicated on figure). The number of proliferating cells was significantly reduced in large $(>500$ $\mu \mathrm{m}$ diameter) $(* P<0.0001)$ medium $\left({ }^{*} P<0.0001\right)$ and small arteries $\left({ }^{\diamond} P<\right.$ 0.02 ) of donor hearts in elafin-treated animals and large $(* P<0.0001)$ and medium vessels $\left({ }^{\dagger} P<0.005\right)$ of elafintreated host hearts. within that group (Table I). Similarly, one of the two elafintreated animals that displayed the greatest degree of fibronectin accumulation was associated with the greatest number of compromised vessels and severity of intimal thickening within the elafin-treated group.
Assessment of cellular proliferation in the coronary arteries. Immunohistochemical studies were performed to assess the effect of elafin on cellular proliferation in the coronary arteries of transplanted hearts. Minimal immunostaining for proliferating cell nuclear antigen was observed in host arteries of

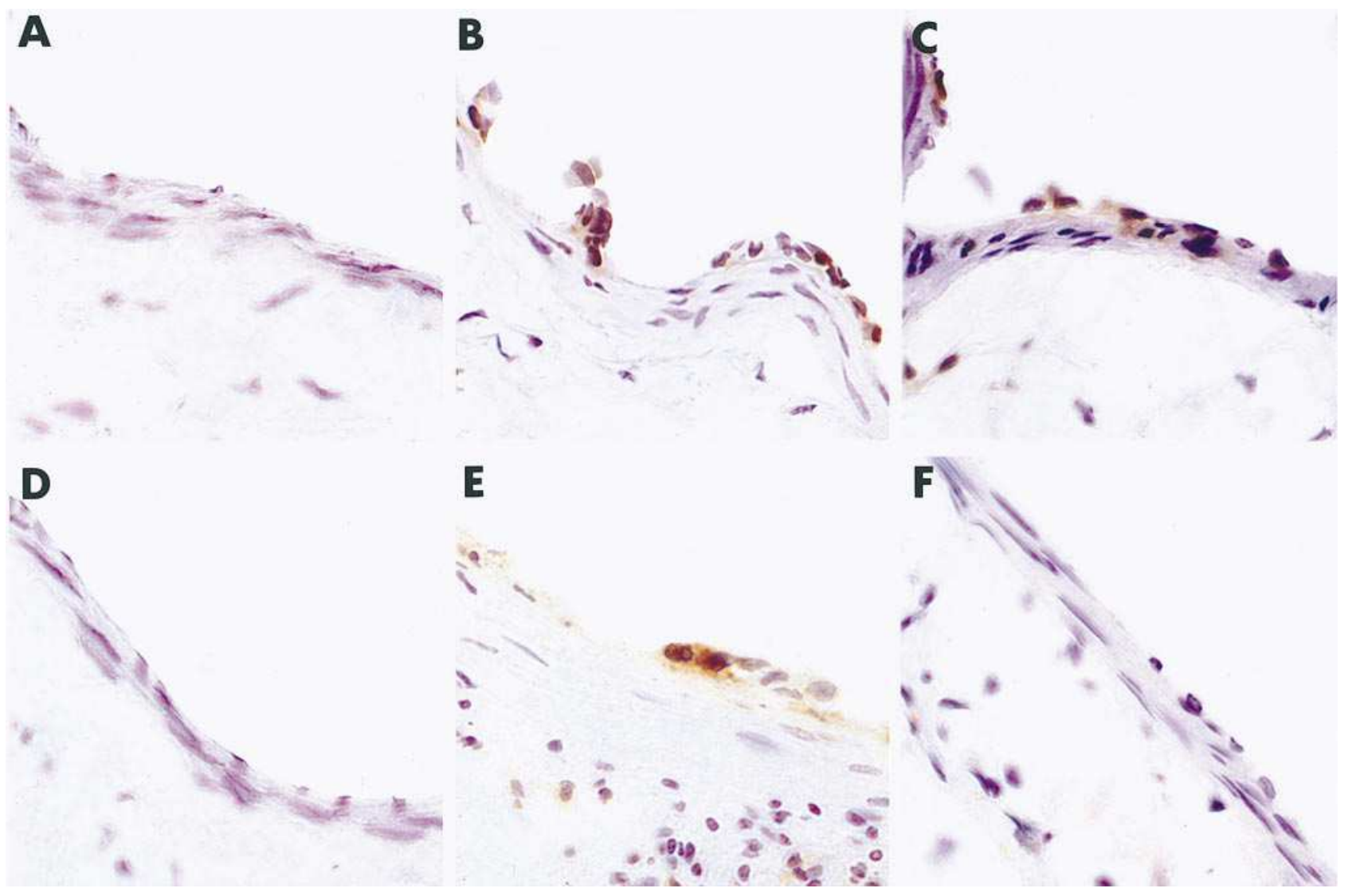

Figure 8. Representative photomicrograph of immunoperoxidase staining for rabbit T cells $(A-C)$ and macrophages $(D-F)$ in host and donor coronary arteries from both control and elafin-treated groups. Negative staining was seen in most host vessels for both $\mathrm{T}$ cells and macrophages ( $A$ and $D$, respectively). In donor vessels of both groups, T cells were abundant both on the endothelial surface and infiltrating the vessel wall ( $B$ and $C$, respectively). Occasionally, macrophages could also be seen adhering to the endothelial cell surface in donor vessels of both groups ( $B$ and $C$, respectively), however, the majority of vessels were negative for this cell type. Macrophages were less evident in the elafin-treated group, and when seen on the coronary arteries they were usually associated with outer medial layer and adventitia. Original magnification 600. 


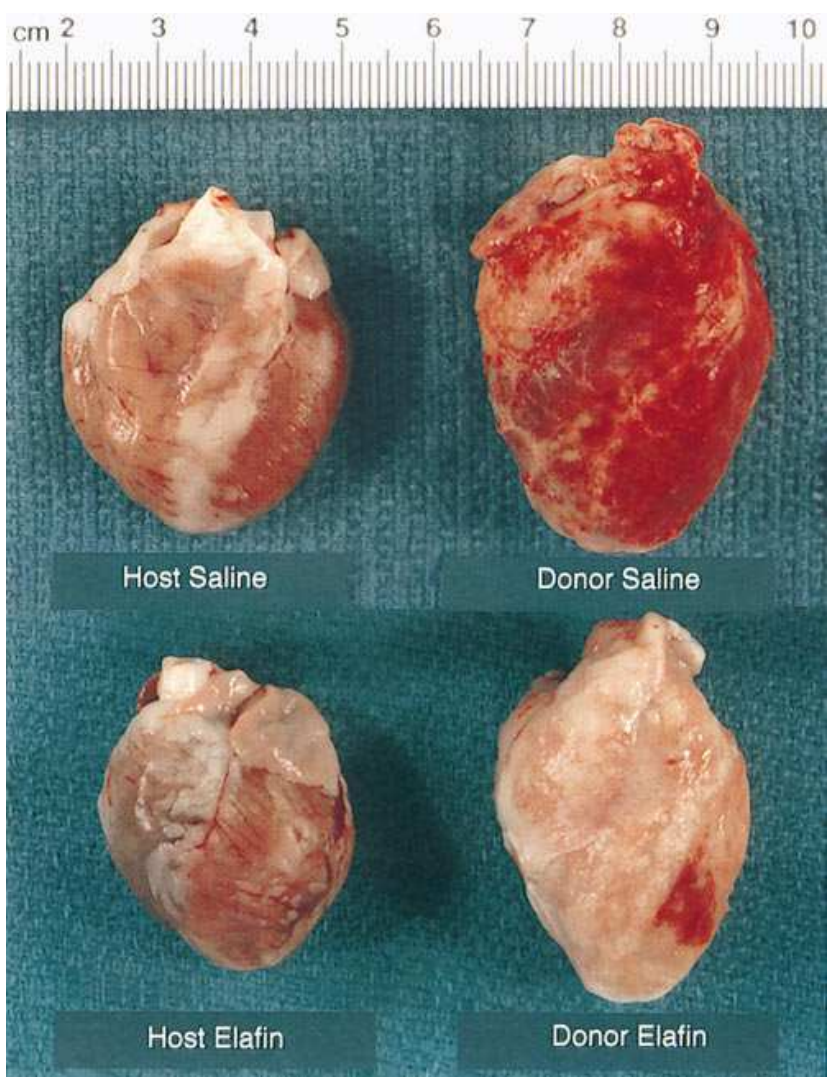

Figure 9. Composite photograph of host and donor rabbit hearts harvested from saline and elafin treated rabbits $1 \mathrm{wk}$ after heterotopic cardiac transplantation. Control (saline) host, control (saline) donor, elafin-treated host, and elafin-treated donor.

control animals (Fig. $6 D$ ). In contrast, the number of positively stained cells both in the media and adventitia was greatly increased in donor coronary arteries of control animals (Fig. $6 E$ ). A significant number of positive cells could also be seen in the intima of vessels with neointimal lesions. In donor coronary arteries of rabbits that received elafin, the level of staining was notably diminished (Fig. $6 F$ ) (Table I). Quantitative assessments are given in Fig. 7. In control host hearts, large coronary arteries showed $\leq 20$ cells that were PCNA positive, whereas $\leq 5$ PCNA positive cells were observed in medium and small vessels. In large donor coronary arteries, no significant difference in the number of PCNA-positive cells was appreciated, but, in medium and small coronary arteries from donor control hearts, a two- to threefold increase was apparent (Fig. 7) $(P<$ 0.0001 and $P<0.0005$, respectively). Elafin-treated donor hearts, however, showed a 96\% $(P<0.0001), 69 \%(P<0.0001)$, and $52 \%(P<0.02)$ decrease in cell proliferation from donor control levels, respectively. A 97 and $79 \%$ decrease in numbers of proliferating cells was also observed in large and medium host arteries of elafin-treated animals when compared to the control group $(P<0.0001$ and $P<0.005$, respectively). A decrease in the basal level of cell proliferation was not observed in small arteries of the elafin-treated host group. Although a general increase in the level of cell proliferation was associated with coronary arteries of the donor control group, there did not appear to be a direct relationship between the number of PCNA-positive cells and either the number of affected arteries or the severity of intimal thickening (individual values given in Table 1). We have not distinguished the number of PCNA-positive cells that were inflammatory versus SMCs, but based upon immunostaining for alpha actin and inflammatory cell markers, we can infer that the majority were likely SMCs.

Immune-inflammatory cells in the coronary arteries. Immunohistochemical studies were performed to compare adhesion and invasion of $\mathrm{T}$ cells and macrophages in host and donor coronary arteries from control and elafin-treated groups. Host coronary arteries were negative for these inflammatory cells. Fig. 8, $A$ and $D$, show examples of negative immunostaining for $\mathrm{T}$ cells and macrophages in host coronary arteries, respectively, whereas donor coronary arteries from both control and elafin groups showed variable expression of these inflamma-

Table II. Immunohistochemical Findings in Allograft Myocardium from Individual Rabbits

\begin{tabular}{|c|c|c|c|c|c|c|c|}
\hline \multirow[b]{2}{*}{ Animal } & \multirow[b]{2}{*}{ Treatment } & \multirow{2}{*}{$\begin{array}{l}\text { Cardiac function } \\
\text { (final) }\end{array}$} & \multicolumn{2}{|c|}{ Grading of rejection } & \multicolumn{2}{|c|}{ Mean number cells $/ 290 \mu \mathrm{m}^{2}$} & \multirow{2}{*}{$\begin{array}{c}\text { Fraction of PCNA } \\
\text { positive cells } \\
\text { (\% total) }\end{array}$} \\
\hline & & & $\%$ Necrosis & \% Inflam & $\mathrm{T}$ cells & Macrophages & \\
\hline 1 & Elafin & Contractile & $22 \%$ & $22 \%$ & 76 & 3 & $16 \%$ \\
\hline 2 & Elafin & Contractile & $23 \%$ & $13 \%$ & 113 & 5 & $5 \%$ \\
\hline 3 & Elafin & Contractile & $31 \%$ & $19 \%$ & 147 & 6 & $9 \%$ \\
\hline 4 & Elafin & Contractile & $21 \%$ & $15 \%$ & 88 & 4 & $8 \%$ \\
\hline 5 & Elafin & Contractile & $24 \%$ & $25 \%$ & 172 & 20 & $7 \%$ \\
\hline 6 & Elafin & Contractile & $19 \%$ & $15 \%$ & 66 & 3 & $10 \%$ \\
\hline 7 & CTRL & Asystolic & $68 \%$ & $28 \%$ & 130 & 9 & $24 \%$ \\
\hline 8 & CTRL & Asystolic & $88 \%$ & $15 \%$ & 111 & 28 & $11 \%$ \\
\hline 9 & CTRL & Asystolic & $85 \%$ & $19 \%$ & 141 & 39 & $38 \%$ \\
\hline 10 & CTRL & Asystolic & $88 \%$ & $8 \%$ & 52 & 36 & $44 \%$ \\
\hline 11 & CTRL & Asystolic & $90 \%$ & $5 \%$ & 55 & 4 & $17 \%$ \\
\hline 12 & CTRL & Asystolic & $90 \%$ & $12 \%$ & 52 & 10 & $45 \%$ \\
\hline
\end{tabular}

CTRL, control ( $0.9 \%$ saline); \% Necrosis, percentage of total ventricular wall area with (necrotic myocytes, replacement or dropout, infiltrative obliteration); \% Inflam (percent inflammation), percentage of total ventricular wall area with (infiltrative obliteration and inflammatory cells); PCNA, proliferating cell nuclear antigen. 

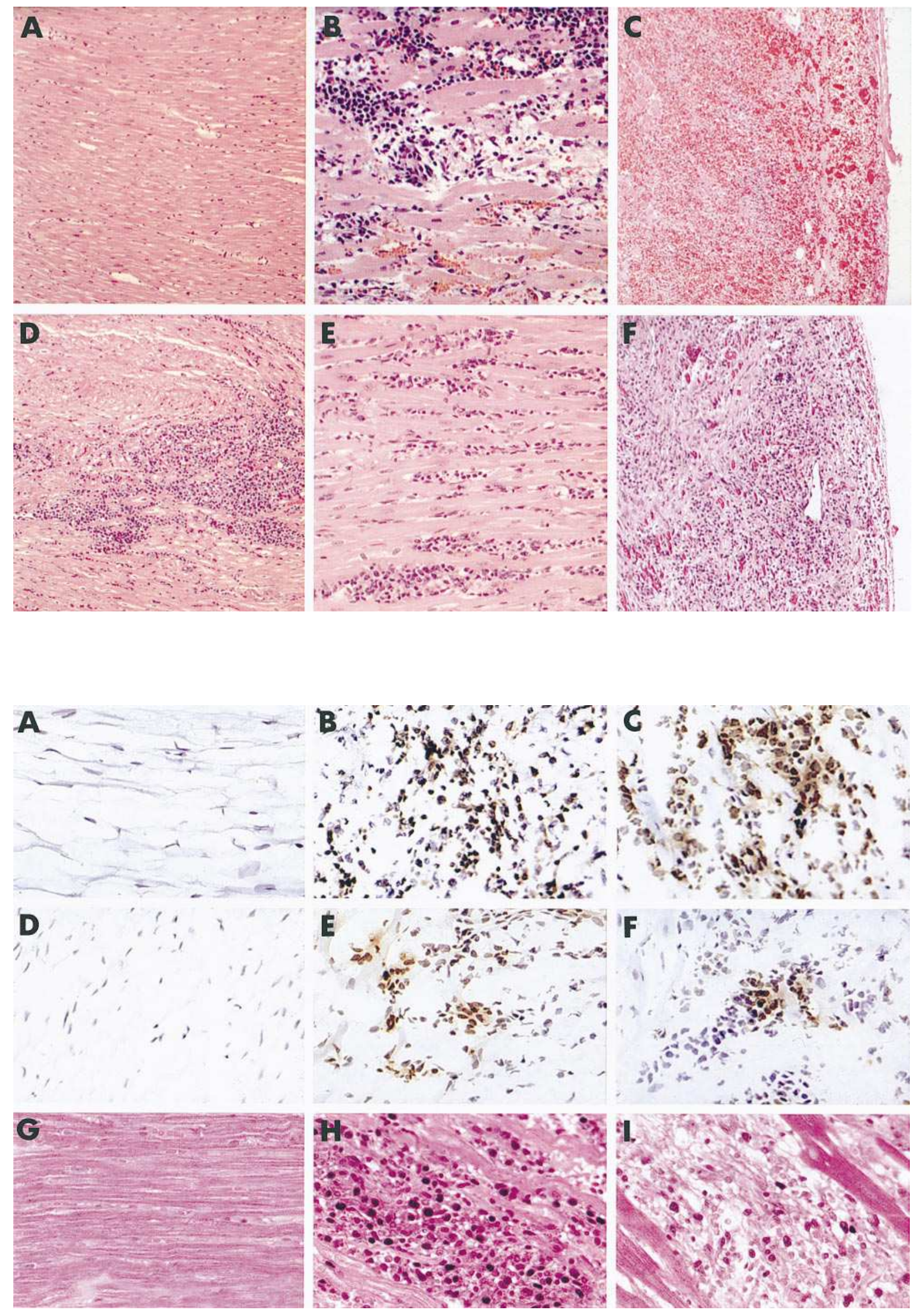
tory cells (Fig. 8, $B$ and $C$, and $E$ and $F$, respectively). T cells were quantitatively judged to be more abundant when the average number of cells per vessel was assessed (Table I). T cells were most often adherent to the endothelium, fewer showed invasion onto the media, and occasionally $\mathrm{T}$ cell presence was observed in the adventitia. Three of six control donor hearts had vessels with 12 or more T cells, two had an average of eight $T$ cells per vessel and one had less than eight. In contrast, only one of six elafin donor hearts showed an average of eight $\mathrm{T}$ cells per vessel, two had less than eight, and three elafin-treated hearts had no T cells associated with their vessels (Table I). In spite of a trend toward decreased numbers of vascular-associated $\mathrm{T}$ cells in elafin-treated animals, average numbers of $\mathrm{T}$ cells associated with vessels in both groups were not significantly different $(P<0.63)$. In neither group was this feature correlated with a reduction in number or severity of arteriopathic lesions.

Macrophages were notably less abundant than T cells, and although they could be found adherent to the endothelial layer, they were most commonly localized in the outer media and adventitia. In control and elafin-treated animals, macrophage presence in donor vessels was determined to range from none to as many as 12 macrophages per vessel (Table I). Although elafin-treated donor hearts showed a greater number of animals negative for vascular-associated macrophages, differences between the two groups was not statistically significant $(P<0.80)$; it is worth noting that both control and elafintreated animals that possessed vascular-associated macrophages had larger numbers of intimal lesions within their respective groups and the greatest increase in the severity of intimal lesion size (Table I).

Evaluation of heart size. The extent of damage to both arteries and myocardium in transplanted hearts without elafin treatment resulted in a lack of function in the donor heart (Table II). This is reflected both in the appearance and in the marked difference in size when compared to hearts from elafin-treated animals (Fig. 9). After experimental heterotopic cardiac transplantation, control and elafin-treated host hearts appeared normal (Fig. 9, $A$ and $C$, respectively) and showed no difference in wet weight at $8.24 \pm 0.34$ and $8.88 \pm 0.38 \mathrm{~g}$, respectively $(n=6)$. However, after saline infusion, donor hearts appeared very hemorrhagic, infiltrated, and edematous (Fig. $9 B$ ) and weighed an average of $25.75 \pm 0.89 \mathrm{~g}$, whereas donor hearts receiving elafin treatment appeared much less hemorrhagic and edematous (Fig. $9 D$ ) and weighed an average of $15.44 \pm 1.14 \mathrm{~g}(n=6)$. Thus, at the termination of the study, donor hearts in saline-treated animals were approximately three times the weight of their respective host hearts $(P<0.0001)$, whereas elafin-treated hearts were only 1.5 times the weight of host hearts $(P<0.002)$. Elafin treatment resulted in a $75 \%$ re- duction in the transplant-induced increase in heart weight $(P<$ 0.0001).

Grading of rejection. Donor heart sections stained with hematoxylin and eosin were qualitatively graded with respect to severity of necrosis and inflammation. Myocardium appeared normal in host hearts from both control (Fig. $10 \mathrm{~A}$ ) and elafintreated rabbits. 1 wk after transplantation, the myocardium of control donor hearts showed infiltration by lymphocytes, macrophages, and granulocytes. This was associated with marked edema, with separation of the myocardial muscle bundles, extensive myocyte necrosis, interstitial hemorrhage, and early fibrosis (Fig. $10 \mathrm{~B}$ ). In contrast, the myocyte integrity of transplanted hearts, in elafin-treated animals, more closely resembled that of nontransplanted hearts in most fields of view. Minimal acute cardiomyocyte necrosis, typically 1-2\% and never exceeding $5 \%$ of any section, was observed in elafin-treated donor hearts although there was extensive lymphocytic infiltration (Fig. $10 \mathrm{E}$ ). Some areas were present, in elafin-treated donor heart sections, where dropout of myocytes, indicative of necrosis, was associated with lymphocytic infiltration (Fig. 10D). In some of these areas there was early replacement fibrosis and areas of infiltrative obliteration. The epicardium and subepicardium of control donor hearts often showed extensive hemorrhage and less cellularity (Fig. $10 \mathrm{C}$ ) than their elafin counterparts (Fig. $10 F$ ).

When the total percentage of left ventricular wall tissue containing areas of acutely necrotic cardiomyocytes, myocyte dropout or replacement with tissue fibrosis and infiltrative obliteration was assessed, elafin-treated donor hearts had an average of $23 \%$ (range $19-31 \%$ ) of the tissue containing areas of necrosis. In contrast, hearts of the saline-treated group showed an average of $85 \%$ (range $68-90 \%$ ) necrotic area in their ventricular wall $(P<0.004)$ (Table II). The percentage of total tissue area assessed as containing inflammation was $18 \%$ (range 13-25\%) in elafin-treated donor hearts, which was similar to donor hearts of the saline-treated group, which received an average score of $14 \%$ (range 5-28\%) $(P=0.29)$ (Table II). Since the category of inflammatory obliteration was included in both the assessments of necrosis and inflammation, addition of the two percentages may exceed $100 \%$, as did occur in three of the controls (Table II).

Immune-inflammatory cells: presence and proliferation in the myocardium. To compare infiltration of $\mathrm{T}$ cells and macrophages in host and donor myocardium from control and elafintreated groups, immunohistochemical studies were performed. Host myocardium was negative for these inflammatory cells. Fig. 11, $A$ and $D$ show examples of negative immunostaining for $\mathrm{T}$ cells and macrophages, respectively. In contrast, donor hearts from both control and elafin-treated groups showed marked expression of both $\mathrm{T}$ cells and macrophages. In control

Figure 10. Representative photomicrographs of hematoxylin- and eosin-stained sections of myocardium from host (control), donor (control), and donor (elafin-treated) groups. Normal myocardium in host hearts $(A)$ contrasts with the severely rejected myocardium observed in the control group $(B$ and $C$ ). The myocytes from elafin-treated donor hearts more closely resemble those in host hearts $(E)$ in spite of inflammatory cell infiltration $(D$ and $F)$. Original magnification $100(A, C, D$, and $F)$ and $200(B$ and $E)$.

Figure 11. Representative photomicrograph of immunoperoxidase staining for T cells $(A-C)$, macrophages $(D-F)$, and PCNA $(G-I)$ in host and donor myocardium from both control and elafin-treated groups. Negative staining was seen in host myocardium for both T cells $(A)$ and macrophages $(D)$. In contrast, donor myocardium of hearts from both control and elafin-treated groups showed extensive infiltration of T cells $(B$ and $C$, respectively) and limited infiltration of macrophages ( $E$ and $F$, respectively). Infiltrating cells in the myocardium showed positive immunoperoxidase staining for PCNA in myocardium from control donor hearts $(H)$. In elafin-treated donor myocardium the level of positive PCNA staining was reduced $(I)$. Myocardium of host hearts was negative for PCNA staining $(G)$. Original magnification 400. 


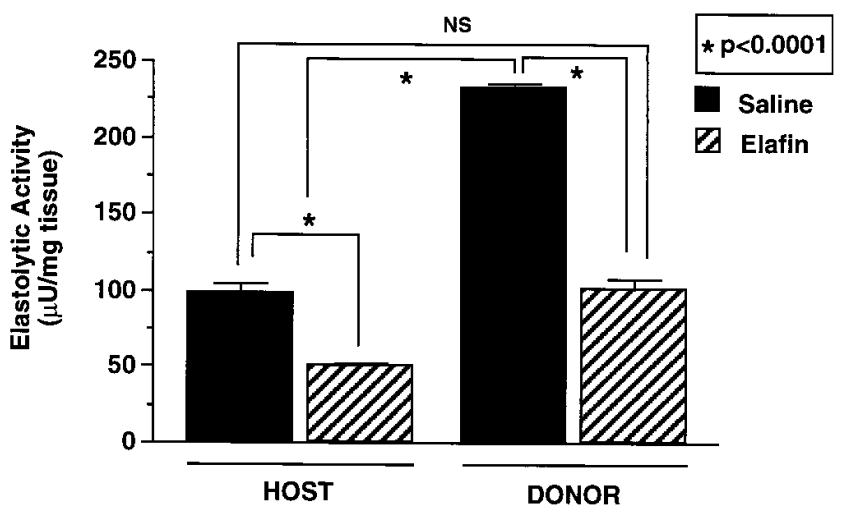

Figure 12. Elastolytic activity of host and donor myocardium from control and elafin-treated hearts. In two separate trials, comparing myocardium from all four groups, increased control donor myocardial elastolytic activity was reduced to control host levels in elafintreated donor myocardium $(* P<0.0001)$. Myocardium from elafintreated host hearts also showed a significant reduction in elastolytic activity $(* P<0.0001)$. Values are mean \pm SEM from a representative experiment.

donor hearts, an average of $90 \pm 17 \mathrm{~T}$ cells and $21 \pm 6$ macrophages were observed per $290 \mu \mathrm{m}^{2}$ of myocardium. In donor hearts of elafin-treated animals an average of $110 \pm 17 \mathrm{~T}$ cells and $7 \pm 3$ macrophages were observed per $290 \mu \mathrm{m}^{2}$ of myocardium (Table II). Neither the numbers of myocardial T cells $(P<$ $0.27)$ or macrophages $(P<0.43)$ were statistically different between the two treatment groups. However, T cells were $\sim 4.5$ times more abundant than macrophages in the donor myocardium of control animals $(P<0.001)$ and 16 times more plentiful in the myocardium of elafin-treated animals $(P<0.0001)$.

$\mathrm{T}$ cells were routinely distributed uniformly throughout the myocardium. Fig. 11, $B$ and $C$ show examples of positive myocardial immunostaining for T cells in control and elafin-treated animals, respectively. Despite lack of statistical significance, $(P<$ $0.43)$, it was interesting that four of six control donor hearts had $\geq 10$ macrophage per $290 \mu \mathrm{m}^{2}$ of myocardium, with three of the four having numbers of 28 and above whereas five of the six elafin-treated rabbits showed $\leq 6$ macrophages per $290 \mu \mathrm{m}^{2}$ of myocardium (Table II). Fig. 11, $E$ and $F$ show examples of positive myocardial immunostaining for macrophages in control and elafin-treated donor hearts, respectively. Unlike the uniform distribution of T cells, macrophages were usually observed in the general vicinity of the coronary vasculature at sites of intense myocardial infiltration. In spite of the similar numbers of both cell types in the donor myocardium of both transplant groups, there was a significant difference in the myocardial rejection grade between the two treatment groups.

Minimal immunostaining for proliferating cell nuclear antigen was observed in host myocardium of control (Fig. $11 \mathrm{G}$ ) and elafin-treated animals (not shown). In contrast, $30 \pm 3 \%$ of cells in the myocardial infiltrate in donor hearts of the saline group showed positive PCNA staining, indicating cellular proliferation (represented in Fig. $11 \mathrm{H}$ ). Infiltrating immune cells from elafin-treated donor hearts showed a twofold reduction in the level of proliferation to $9 \pm 1 \%(P<0.0001)$, which is represented in Fig. $11 \mathrm{I}$. Proliferation rates for individual animals are listed in Table II.

Myocardial elastolytic activity. In four animals we were able to analyze tissue for myocardial elastase activity. Myocar- dial protein extracts from donor hearts of control animals showed a greater than onefold increase in elastolytic activity per milligram of tissue, judged by degradation of a $\left[{ }^{3} \mathrm{H}\right]$-insoluble elastin substrate, when normalized and compared to host controls $(P<0.0001)$ (Fig. 12). In contrast, protein extracted from the donor myocardium of elafin-treated animals showed elastolytic activity similar to the host controls. Myocardial protein extracts from elafin-treated host hearts, however, also showed a $52 \%$ reduction in elastolytic activity compared to the values of control group host myocardium $(P<0.0001)$. A mean value \pm SEM is shown from a representative experiment.

Lymphocyte elastolytic activity. To determine whether infiltrating $\mathrm{T}$ cells could be a contributing source of myocardial elastase activity, we isolated peripheral blood $\mathrm{T}$ cells from two nontransplanted rabbits and assessed their ability to degrade insoluble $\left[{ }^{3} \mathrm{H}\right]$ elastin, as a measure of elastolytic activity. We observed that $5 \times 10^{5}$ lymphocytes degraded $\sim 550 \mathrm{ng}$ of insoluble elastin. This activity was suppressed by $75 \%$ after the administration of $1 \mu \mathrm{g}$ of recombinant human elafin $(P<0.01)$. Lymphocytes isolated from heparinized peripheral blood of a transplanted rabbit did not differ in either the magnitude of basal elastolytic activity or in the level of inhibition by exogenous elafin.

\section{Discussion}

In this study, we describe the positive effect of elafin, a selective serine elastase inhibitor, in markedly attenuating both the development of experimental graft arteriopathy and the associated myocardial necrosis in vivo. These are the first observations to provide evidence of a functional role for increased elastolytic activity in the pathophysiology of this disease. We were able to show that the decrease in both the incidence and severity of allograft coronary artery lesions in the elafintreated group was associated with inhibition of elastolytic activity judged ultrastructurally, and fibronectin production and vascular cell proliferation assessed immunohistochemically. These results suggest that inhibition of elastolytic activity prevents the cytokine-mediated upregulation of fibronectin in donor vessels which we have previously described $(56,70)$. Increased fibronectin has been previously shown to mediate both smooth muscle cell migration into the subendothelium (71) and transendothelial migration of inflammatory cells (12, $18,19)$. In addition, it is likely that elafin also interfered with the elastase-mediated release of matrix-bound growth factors that cause smooth muscle cell proliferation (37), which is known to precede neointimal lesion development (72-76). We could conclude, therefore, that elafin influences the process of intimal thickening in the setting of the allograft arteriopathy, primarily by its direct and indirect effects on smooth muscle cell migration and proliferation. Elafin did not, however, despite its modulation of fibronectin, appear to influence inflammatory cell transendothelial migration, implicating other mechanisms, e.g., production of metalloenzymes (77). An unexpected finding was that administration of elafin also limited the increase in donor heart size and decreased myocardial necrosis observed in control hearts. This was associated with an inhibition of donor myocardial elastolytic activity, and a significant depression in the proliferation of infiltrating inflammatory cells. We related these features to elafin-mediated inhibition of basal lymphocyte elastolytic activity, in vitro, and to 
direct and indirect effects of elafin on cell proliferation (which will be discussed).

The rabbit heterotopic cardiac transplant model has proven to be useful in studying the pathophysiologic mechanisms underlying the development of graft arteriopathy and myocardial rejection $(12,18,60,62)$. The allograft arterial lesions in this model develop over an accelerated time course $(18,60)$. However, as the lesions resemble those observed in human allografts (62), the model offers a time-efficient method of studying the factors contributing to this disease process. In the rabbit model, lack of immunosuppression is required to accelerate neointimal lesion development (18), which occurs before complete allograft rejection at $7-8 \mathrm{~d}(18,60)$. In the presence of immunosuppression, these lesions still develop but over a longer time course (i.e., 5-6 wk) $(63,78)$.

Animals were also made hypercholesterolemic to elevate the normally low cholesterol levels in rabbits and further accelerate the development of the arteriopathy $(20,60,79,80)$. After consumption of a $0.5 \%$ cholesterol diet, the intimal lesions are fatty proliferative in nature and bear close resemblance to chronic posttransplant coronary arteriopathy lesions seen in the human disease (60). Elevated rabbit serum cholesterol is also reflected in the early induction of intimal lesions in host vessels and fatty infiltration of the myocardium (18). In the absence of an increased cholesterol diet, arteriopathic lesions develop over a longer time course and are characterized as predominantly proliferative in nature (60).

Evidence of increased elastolytic activity in coronary arteries from cardiac biopsy and postmortem tissue of transplant recipients (4) has been suggested by morphologic evidence of disruption of the internal elastic lamina (16). We have correlated the ultrastructural appearance of fragmentation of elastin with increased serine elastase activity in coronary arteries from piglets after cardiac transplantation (17). Increased elastolytic activity has also been associated with atherosclerosis $(81,82)$ and increasing evidence supports the involvement of both metallo- $(26,27)$ and cysteine proteinases $(83)$ in vulnerable regions of atherosclerotic plaques. We have previously reported increased levels of serine elastolytic activity in experimental models of pulmonary hypertension (84-87) and in association with neointimal proliferation in an organ-culture model of atherogenesis (88). In experimental models of pulmonary vascular disease, elastase inhibitors were found to reduce pulmonary hypertension significantly, and to reduce vascular changes, including early evidence of neointimal formation $(84,85,87)$. Elastases may function to liberate growth factors from the matrix and to upregulate cytokine activity and, in this way, contribute to the development of neointimal lesions (37$47)$. Elastase activity also results in the production of chemotactic peptides $(29,48,49)$, which may influence both lymphocyte transendothelial migration and SMC migration into the subendothelium.

The contributing sources of elastolytic activity in the vascular allograft remain to be determined. However, primary candidates are trafficking inflammatory cells and vascular smooth muscle cells. Both allogenic CD4+ and CD8+ T lymphocytes secrete granzyme serine proteinases (89-91), and granzyme A is known to be elastolytic (91). Macrophages secrete elastolytic serine proteinases indistinguishable from leukocyte elastase and cathepsin $\mathrm{G}(30,92,93)$. These inflammatory cells have been extensively documented both in the coronary vasculature $(12,18-21)$ and in the rejecting myocardium (22-24) after car- diac transplantation. Coronary artery smooth muscle cells could also contribute to the increased elastolytic activity observed (56).

In vitro, we have demonstrated that IL- $1 \beta$-stimulated coronary artery smooth muscle cell fibronectin synthesis is reduced to basal levels by the administration of either the serine proteinase inhibitor, alpha- 1 antitrypsin, or the specific elastase inhibitor, elafin (70) and that this is correlated with reduced production of elastin peptides (56). As k-elastin, a fragmented form of insoluble elastin, has been shown to upregulate fibronectin synthesis in cultured vascular smooth muscle cells by facilitating the interaction between IL-1 $\beta$ and its receptor (52a), we postulate that elastin peptides may have the same effect in vivo in coronary allograft arteriopathy by promoting cytokine-mediated endothelial and smooth muscle cell fibronectin synthesis.

Elafin's selectivity and, specifically, its inhibition of elastase(s) isolated from heterotopically transplanted piglet donor coronary arteries (17), and its inhibition of IL-1 $\beta$-stimulated coronary artery smooth muscle cell fibronectin synthesis in vitro (70), made it an excellent candidate for the assessment of the pathophysiologic role of elastolytic activity in the rabbit model of post-cardiac transplant coronary arteriopathy. Recombinant human elafin is a $6-\mathrm{kD}$ (57 amino acid), highly charged, acid-stable, basic polypeptide with a $38 \%$ sequence homology with the $\mathrm{COOH}$-terminal half of antileukoproteinase (59). Elafin, initially purified from human psoriatic lesions (59) and later from bronchial mucus of patients with chronic bronchitis (55), is a potent, substrate-like, fully reversible inhibitor of human leukocyte elastase $(57,59)$, porcine pancreatic elastase (59), and proteinase 3 (58). Elafin inactivates serine elastases by blocking the reactive serine at the catalytic center (57) and blocks both human leukocyte elastase and porcine pancreatic elastase at a 1:1 molar concentration (59). Elafin has no effect on plasmin, trypsin, $\alpha$-chymotrypsin, and cathep$\sin \mathrm{G}$ making it a very selective elastase inhibitor $(58,59,94)$. In addition, it has been reported that IL- $1 \beta$, TNF- $\alpha$, human neutrophil elastase, and cathepsin $\mathrm{G}$ are major inducers of elafin/pre-elafin expression in two human airway epithelial cell lines (95). Elafin has also been shown to reduce reperfusion neutrophil recruitment and preserve post-ischemic skeletal muscle viability, in vivo (96). Elafin appears to be constitutively expressed in the vasculature (97) and our unpublished observations and may be a naturally occurring inhibitor, which could be suppressed or sequestered in disease. Recently, it was proposed in studies of mammary epithelial cells that intracellular elafin expression may even have direct effects inhibiting cell cycle progression and proliferation (98). If so, this may also contribute to the observed reduction in smooth muscle and inflammatory cell proliferation.

Elafin treatment did not appear to influence the number or severity of host vessels with lesions. This feature was also appreciated in our studies using the TNF- $\alpha$ sr (18) and CS-1 peptide (12), but not in studies with other agents used to reduce graft arteriopathy $(63,78)$. This reinforces a selective effect of elafin on the pathophysiology of graft arteriopathy.

In developing the quantitative assessment of rejection for the present study, the cardiac biopsy grading scheme established by the Heart Rejection Study Group of the International Society for Heart and Lung Transplantation (99), a modified version of the Billingham grading scheme (100), was not used for several reasons. It is not quantitative; it is de- 
signed for the assessment of endomyocardial biopsies not transmural sections and is more appropriate to clinical practice as contrasted with the nonimmunosuppressed outbred heterotopic rabbit heart transplant model of the present study in which rejection was so severe in the control animals that at 7-d follow-up none of these hearts remained beating. Nevertheless, our assessment of rejection retained the key elements of all systems for grading cardiac rejection: the distinction between the presence of inflammatory activity and cardiomyocyte necrosis. The quantitative assessment was not performed in a blinded fashion because qualitative differences in heart sections from the two groups, assessed previously, were so distinctive.

The $62 \%$ mean reduction in necrotic left ventricular wall area after elafin administration differed from previous studies in our laboratory in which significant reduction in both the number of arteries with neointimal lesions and severity of lesions was accomplished without altering the associated myocardial necrosis $(12,18)$. It is likely that elastases released from both infiltrating inflammatory cells and from vascular cells function to disrupt myocyte integrity and the myocardial architecture. Matrix metalloproteinases and human leukocyte elastase are capable of myocardial disruption through the degradation of fibrillar collagen (101), and macrophage proteinases have been shown to degrade a wide variety of extracellular matrix components, including elastin and collagen (102, 103). Serine proteinases have also been shown to activate myocardial promatrix metalloproteinases that have been localized to the endocardium, subendocardium, and the interstitium (101). Allogenic T lymphocytes are know to possess granzymes $\mathrm{A}$ and $\mathrm{B}$ and perforin, which are effectors of foreign cell destruction $(89,90)$. The presence of granzyme A, granzyme B, and perforin in prerejected myocardial biopsies suggests that these proteins could be used as predictive markers for acute rejection in patients with early rejection crisis (104-106) and possibly function in the cytolysis that occurs during transplantation rejection (104). Also, serine proteinase inhibitors of $\mathrm{T}$ lymphocyte natural cytotoxicity have been shown to block cytotoxic activity without affecting lymphocyte-target cell binding (107). This provides further support that serine proteinases may be involved in the initiation of the cascade of events that may lead to cytolysis (107).

Although allogenic T lymphocytes and macrophages have been extensively documented in donor coronary arteries (12, 18-21) and the rejecting posttransplant myocardium (22-24), macrophages are not a prominent early feature of the rabbit accelerated graft arteriopathy model $(12,18,20)$. Accordingly, we have observed relatively fewer macrophages adherent to the coronary vasculature and infiltrating the myocardium. Macrophages become a significantly more prominent feature of rabbit cardiac allografts 2-3 wk after experimental transplantation (20) and are also prevalent in human cardiac allografts only years after cardiac transplantation $(22,23)$. Thus, we chose to focus on the potential elastolytic contribution of the extensive $\mathrm{T}$ cell infiltrate to myocardial necrosis. In this study, we demonstrated that isolated rabbit peripheral blood lymphocytes possess elafin-inhibitable elastase activity, although we cannot exclude potential contribution from other sources. This activity may be elevated after both lymphocyte adhesion to the cardiac allograft and stimulation by cytokines and soluble factors in the graft microenvironment.

Elafin administration resulting in a $67 \%$ reduction in the percentage of proliferating cells as judged by the presence of PCNA suggests that elafin's limiting effect on myocardial necrosis may also be mediated by a reduction in the clonal proliferation rate of infiltrating inflammatory cells. As observed in the vasculature, this may be the result of elafin's reductive effect on the liberation of matrix-bound growth factors involved in cell proliferation (37) and perhaps its speculative role as an inhibitor of cell cycle progression (98). In spite of the $21 \%$ increase in the number of PCNA-positive cells observed in saline-treated donor hearts, there was, if anything, a trend toward increased numbers of inflammatory cells in elafin-treated hearts $(P=0.06)$. That the increase in PCNA-positive cells was not reflected in an increase in cell number may either mean that, despite proliferation, there is high cell turnover or that there is lack of progression to cell division. Inflammatory cell proliferation has been documented in rat cardiac allografts irrespective of the form of immunosuppression (108). In these studies, CD8 $+\mathrm{T}$ cell proliferation rates ranged from 15 to $37 \%$ and $\mathrm{CD} 4+\mathrm{T}$ cell proliferation rates ranged from 25 to $30 \%$. In contrast, macrophage proliferation within the graft was minimal at 1 to $4 \%$ (108), suggesting, as in our study, that $\mathrm{T}$ cells are the major proliferating cell population. Although steroid immunosuppression eliminated signs of graft destruction, no effect was observed on the levels of inflammatory cell proliferation (108). These observations indicate that elafin may reduce myocardial necrosis through a reduction of both the number of clonally proliferating inflammatory cells and also through an inhibitory effect on their proteolytic enzymes.

In summary, we have used elafin to show that the reduction of experimental accelerated graft arteriopathy induced in cholesterol-fed rabbits after heterotopic cardiac transplantation can be achieved by reducing vascular-associated elastolytic activity. We propose that the reduced production of elastin peptides in the vasculature impairs cytokine-mediated stimulation of endothelial and smooth muscle cell fibronectin synthesis which influences the migration of smooth muscle and inflammatory cells. Elafin also reduces the liberation of matrix-bound growth factors which may be responsible for the proliferation of vascular smooth muscle cells. We have also shown that administration of elafin causes a reduction in posttransplant myocardial necrosis. Since elafin reduced the elastolytic activity of isolated lymphocytes, we speculate that elastolytic activity produced by these cells contributes to transplant-associated myocardial necrosis. Therefore, it is possible that local inhibition of elevated elastolytic activity may offer alternative or accessory therapy for the effective prevention of both graft arteriopathy and myocardial necrosis.

\section{Acknowledgments}

We thank Mike Starr for the preparation of the color photomicrographs and Joan Jowlabar and Susy Taylor for secretarial assistance. We thank Julia Hwang, Lily Morikawa, and the other members of the Department of Pathology at The Hospital for Sick Children for their microscopic and histological assistance. We are indebted to the staff of the Animal Care Facility at The Hospital for Sick Children for their support with the animal care.

Bryce Cowan was supported by a Heart and Stroke Foundation Studentship, Julie Crack by a University of Toronto Studentship through the Collaborative Cardiovascular Sciences Program, and Drs. Wilson and Rabinovitch are Career Investigators of the Heart and Stroke Foundation of Ontario. This work was supported by a Program Grant PG12351 from the Medical Research Council of Canada. 


\section{References}

1. Bieber, C., S. Hunt, D. Schwinn, S. Jamieson, B. Reitz, P. Oyer, N. Schumway, and E. Stinson. 1981. Complications in long-term survivors of cardiac transplantation. Transplant. Proc. 13:207-211.

2. Jamieson, S., P. Oyer, B. Reitz, W. Baumgartner, C. Bieber, E. Stinson, and N. Shumway. 1981. Cardiac transplantation: the Stanford experience. J. Heart Transplant. 1:86-91.

3. Uretsky, B., R. Kormos, T. Zerbe, A. Lee, T. Tokarczyk, S. Murali, S. Reddy, B. Denys, B. Griffith, R. Hardesty, J. Armitage, and V. Arena. 1992. Cardiac events after heart transplantation: incidence and predictive value of coronary arteriopathy. J. Heart Lung Transplant. 11:S45-S51.

4. Billingham, M.E. 1994. Pathology and etiology of chronic rejection of the heart. Clin. Transplantation. 8:289-292.

5. Libby, P., and H. Tanaka. 1994. The pathogenesis of coronary arteriosclerosis ("chronic rejection") in transplanted hearts. Clin. Transplantation. 8: 313-318

6. Jakel, K.T., and T. Loning. 1993. Herpes virus infections, acute rejection, and transplant arteriosclerosis in human cardiac allografts. Transplant. Proc. 25(2):2029-2030

7. Hayry, P., T. Paavonen, A. Mennander, J. Ustinov, A. Raisanen, and K. Lemstrom. 1993. Pathophysiology of allograft arteriosclerosis. Transplant. Proc. 25(2):2070.

8. Wanders, A., M.L. Akyurek, J. Waltenberger, C. Stafberg, E. Larsson, R. Zhiping, K. Funa, and B. Fellstrom. 1993. Impact of ischemic time on chronic vascular rejection in the rat-effects of angiopeptin. Transplant. Proc. 25(2): 2098-2099.

9. Libby, P., S. Swanson, H. Tanaka, A. Murray, F. Schoen, and J. Pober. 1992. Immunopathology of coronary arteriosclerosis in transplanted hearts. J. Heart Lung Transplant. 11:S5-S6.

10. Clausell, N., and M. Rabinovitch. 1993. Upregulation of fibronectin synthesis by interleukin-1 $\beta$ in coronary artery smooth muscle cells is associated with the development of the post-cardiac transplant arteriopathy in piglets. J. Clin. Invest. 92:1850-1858.

11. Molossi, S., N. Clausell, and M. Rabinovitch. 1993. Coronary artery endothelial interleukin-1 $\beta$ mediates enhanced fibronectin production related to post-cardiac transplant arteriopathy in piglets. Circulation. 88:248-256.

12. Molossi, S., M. Elices, T. Arrhenius, R. Diaz, C. Coulber, and M. Rabinovitch. 1995. Blockade of very late antigen-4 integrin binding to fibronectin with connecting segment-1 peptide reduces accelerated coronary arteriopathy in rabbit cardiac allografts. J. Clin. Invest. 95:2601-2610.

13. Carlos, T., B. Schwartz, N. Kovach, E. Yee, M. Rosa, L. Osborn, G. ChiRosso, B. Newman, R. Lobb, and J. Harlan. 1990. Vascular cell adhesion molecule-1 mediates lymphocyte adherence to cytokine-activated cultured human endothelial cells. Blood. 76:965-970.

14. Jonjic, N., P. Jilek, S. Bernasconi, G. Peri, I. Martin-Padura, S. Cenzuales, E. Dejana, and A. Mantovani. 1992. Molecules involved in the adhesion and cytotoxicity of activated monocytes on endothelial cells. J. Immunol. 148: 2080-2083.

15. Billingham, M. 1992. Histopathology of graft coronary disease. J. Heart Lung Transplant. 11:S38-S44.

16. Ardehali, A., A. Billingsley, H. Laks, D.C. Drinkwater, T.J. Sorensen, and T.A. Drake. 1993. Experimental cardiac allograft vasculopathy in mice. J. Heart Lung Transplant. 12:730-735.

17. Oho, S., and M. Rabinovitch. 1994. Post-cardiac transplant arteriopathy in piglets is associated wit fragmentation of elastin and increased activity of a serine elastase. Am. J. Pathol. 145:202-210.

18. Clausell, N., S. Molossi, S. Sett, and M. Rabinovitch. 1994. In vivo blockade of tumor necrosis factor- $\alpha$ in cholesterol-fed rabbits after cardiac transplant inhibits acute coronary artery neointimal formation. Circulation. 89:2768-2779.

19. Clausell, N., S. Molossi, and M. Rabinovitch. 1993. Increased interleukin-1 $\beta$ and fibronectin expression are early features of the development of the postcardiac transplant coronary arteriopathy in piglets. Am. J. Pathol. 142: $1772-1786$.

20. Kuwahara, M., J. Jacobsson, M. Kuwahara, E. Kagan, P.W. Ramwell, and M.L. Foegh. 1991. Coronary artery ultrastructural changes in cardiac transplant atherosclerosis in the rabbit. Transplantation. (Baltimore). 52:759-765.

21. Tanaka, H., G.K. Sukhova, S.J. Swanson, M.I. Cybulsky, F.J. Schoen, and P. Libby. 1994. Endothelial and smooth muscle cells express leukocyte adhesion molecules heterogeneously during acute rejection of rabbit cardiac allografts. Am. J. Pathol. 144:938-951.

22. Gassel, A.M., H.-J. Radzun, M.-L. Hansmann, M. Weyand, and W. Konertz. 1989. Monocytes and macrophages in the rejection of human cardiac allografts. Transplant. Proc. 21:2514-2516.

23. Gassel, A.M., M.-L. Hansmann, H.-J. Radzun, and M. Weyand. 1990. Human cardiac allograft rejection. Correlation of grading with expression of different monocyte/macrophage markers. Am. J. Clin. Pathol. 94:274-279.

24. Hayashi, T., M. Nozawa, I. Otsu, D. Hirofumi, Y. Kitaura, and K. Kawamura. 1991. Cell-mediated cytotoxicity in acute rat cardiac allograft rejection: an immunological and ultrastructural study. Virchows Archiv. A Pathol. Anat. 418:41-50
25. Campbell, E.J., J.D. Cury, S.D. Shapiro, G.I. Goldberg, and H.G. Welgus. 1991. Neutral proteinases of human mononuclear phagocytes. Cellular differentiation markedly alters cell phenotype for serine proteinases, metalloproteinases, and tissue inhibitor of metalloproteinases. J. Immunol. 146:1286-1293.

26. Brown, D.L., M.S. Hibbs, M. Kearney, C. Loushin, and J.M. Isner. 1995. Identification of $92-\mathrm{kD}$ gelatinase in human coronary atherosclerotic lesions. Circulation. 91:2125-2131.

27. Galis, Z.S., G.K. Sukhova, M.W. Lark, and P. Libby. 1994. Increased expression of matrix metalloproteinases and matrix degrading activity in vulnerable region of human atherosclerotic plaques. J. Clin. Invest. 94:2493-2503.

28. Shapiro, S., D. Kobayashi, A. Pentland, and H. Welgus. 1993. Induction of macrophage metalloproteinases by extracellular matrix. J. Biol. Chem. 268 8170-8175.

29. Senior, R., N. Connolly, J. Cury, H. Welgus, and E. Campbell. 1989. Elastin degradation by human alveolar macrophages: a prominent role of metalloproteinase activity. Am. Rev. Respir. Dis. 139:1251-1256.

30. Campbell, E.J., E.K. Silverman, and M.A. Campbell. 1989. Elastase and cathepsin $\mathrm{G}$ of human monocytes. Quantification of cellular content, release in response to stimuli, and heterogeneity in elastase-mediated proteolytic activity. J. Immunol. 143:2961-2968.

31. Hudig, D., N.J. Allison, T.M. Pickett, U. Winkler, C.-M. Kam, and J.C Powers. 1991. The function of lymphocyte proteases. Inhibition and restoration of granule-mediated lysis with isocoumarin serine protease inhibitors. J. Immunol. 147:1360-1368.

32. Takahashi, H., T. Nukiwa, P. Basset, and R.G. Crystal. 1988. Myelomonocytic cell lineage expression of the neutrophil elastase gene. J. Biol. Chem. 263:2543-2547.

33. Zhu, L., D. Wigle, A. Hinek, J. Kobayashi, Y. Chongliang, M. Zucker, H. Dodo, F. Keeley, and M. Rabinovitch. 1994. The endogenous vascular elastase that govern development and progression of monocrotaline-induced pulmonary hypertension in rats is a novel enzyme related to the serine proteinase adipsin. J. Clin. Invest. 94:1163-1171.

34. Kobayashi, J., D. Wigle, T. Childs, L. Zhu, F. Keeley, and M. Rabinovitch. 1994. Serum-induced vascular smooth muscle cell elastolytic activity through tyrosine kinase intracellular signalling. J. Cell. Physiol. 160:121-131.

35. Galis, Z.S., M. Muszynski, G.K. Sukhova, E. Simon-Morrissey, E.N Unemori, M.W. Lark, E. Amento, and P. Libby. 1994. Cytokine-stimulated human vascular smooth muscle cells synthesize a complement of enzymes required for extracellular matrix digestion. Circ. Res. 75:181-189.

36. Croute, F., E. Delaporte, J. Bonnefoy, C. Fertin, J. Thivolet, and J. Nicolas. 1991. Interleukin-1 $\beta$ stimulates fibroblast elastase activity. $B r . J$. Dermatol. 124:538-541.

37. Thompson, K., and M. Rabinovitch. 1996. Exogenous leukocyte and endogenous elastases can mediate mitogenic activity in pulmonary artery smooth muscle cells by release of extracellular matrix-bound basic fibroblast growth factor. J. Cell. Physiol. 166:495-505.

38. Saksela, O., D. Moscatelli, A. Sommer, and D. Rifkin. 1988. Endothelial cell-derived heparin sulfate binds basic fibroblast growth factor and protects it from proteolytic degradation. J. Cell Biol. 107:743-751.

39. Klagsburn, M., and E. Edelman. 1989. Biological and biochemical properties of fibroblast growth factors: implications for the pathogenesis of atherosclerosis. Atherosclerosis. 9:269-278.

40. Lyons, R., J. Keski-Oja, and H.L. Moses. 1988. Proteolytic activation of latent transforming growth factor beta from fibroblast conditioned medium. J. Cell Biol. 106:1659-1665.

41. Sato, Y., and D. Rifkin. 1989. Inhibition of endothelial cell movement by pericytes and smooth muscle cells: activation of a latent form of transforming growth factor- $\beta 1-$ like molecule by plasmin during co-culture. J. Cell Biol. 109:309-315.

42. Taipale, J., K. Koli, and J. Keski-Oja. 1992. Release of transforming growth factor $\beta 1$ from the pericellular matrix of cultured fibroblasts and fibrosarcoma cells. J. Biol. Chem. 267:25378-25384.

43. Mueller, S., A. Patterson, and J. Kudlow. 1990. Transforming growth factor alpha in arterioles: cell surface processing of its precursor by elastase. Mol. Cell. Biol. 10:4596-4602.

44. Cappelluti, E., S.C. Strom, and R.B. Harris. 1993. Potential role of two novel elastase-like enzymes in processing pro-transforming growth factor- $\alpha$. Biochemistry. 32:551-560.

45. Hazuda, D.J., J. Strickler, F. Kueppers, P.L. Simon, and P.R. Young. 1990. processing of precursor interleukin $1 \beta$ and inflammatory disease. J. Biol. Chem. 265:8318-8322.

46. Suter, S., C. Shaab, P. Roux-Lombard, E. Giradin, G. Grau, and J. Dayer. 1988. Relation between tumor necrosis factor- $\alpha$ and granulocyte- $\alpha 1$ proteinase inhibitor complexes in the plasma of patients with cystic fibrosis. Am. Rev. Respir. Dis. 140:1640-1644.

47. Hebert, C.A., F.W. Luscinskas, J.-M. Kiely, E.A. Luis, W.C. Darbonne, G.L. Bennett, C.C. Liu, M.S. Obin, M.A. Gimbrone, Jr., and J.B. Baker. 1990 Endothelial and leukocyte forms of IL-8 conversion by thrombin and interactions with neutrophils. J. Immunol. 145:3033-3040.

48. Werb, Z., P. Tremble, O. Behrendtsen, E. Crowley, and C. Damsky. 1989. Signal transduction through the fibronectin receptor induces collagenase and stromelysin gene expression. J. Cell Biol. 109:877-889. 
49. Senior, R.M., G.L. Griffin, R.P. Mecham, D.S. Wrenn, K.U. Prasad, and D.W. Urry. 1984. Val-Gly-Val-Ala-Pro-Gly, a repeating peptide in elastin, is chemotactic for fibroblasts and monocytes. J. Cell Biol. 99:870-874.

50. Molossi, S., M. Elices, T. Arrhenius, and M. Rabinovitch. 1995. Lymphocyte transendothelial migration toward smooth muscle cells in interleukin$1 \beta$ stimulated co-cultures is related to fibronectin interactions with $\alpha 4 \beta 1$ and

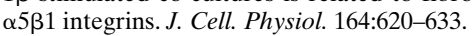

51. Molossi, S., N. Clausell, and M. Rabinovitch. 1995. Reciprocal induction of tumor necrosis factor- $\alpha$ and interleukin- $1 \beta$ activity mediates fibronectin synthesis in coronary artery smooth muscle cells. J. Cell. Physiol. 163:19-29.

52. Molossi, S., N. Clausell, S. Sett, and M. Rabinovitch. 1994. Neutralization of tumor necrosis factor-alpha reduces expression of vascular adhesion molecules and associated intimal thickening in rabbit cardiac allografts. J. Am. Coll. Cardiol. Feb:140A.

52a. Hinek, A., S. Molossi, and M. Rabinovitich. 1996. Functional interplay between interleukin-1 receptor and elastin binding protein regulates fibronectin production in coronary artery smooth muscle cells. Exp. Cell Res. 225:In press.

53. Sallenave, J.-M., and A. Silva. 1993. Characterization and gene sequence of the precursor of elafin an elastase-specific inhibitor in bronchial secretions. Am. J. Respir. Cell Mol. Biol. 8:439-445.

54. Sallenave, J.-M., M.D. Marsden, and A.P. Ryle. 1992. Isolation of elafin and elastase-specific inhibitor (ESI) from bronchial secretions. Biol. Chem. Hoppe-Seyler. 373:27-33.

55. Sallenave, J.-M., and A. P. Pyle. 1991. Purification and characterization of elastase-specific inhibitor. Biol. Chem. Hoppe-Seyler. 372:13-21.

56. Cowan, B., C. Coulber, and M. Rabinovitch. 1995. Elastolytic activity mediates cytokine induced fibronectin synthesis in post-transplant coronary arteriopathy. Can. J. Cardiol. 11(Suppl E):109E.

57. Ying, Q.-L., and S.R. Simon. 1993. Kinetics of the inhibition of human leukocyte elastase by elafin, a 6-kilodalton elastase specific inhibitor from human skin. Biochemistry. 32:1866-1874.

58. Wiedow, O., J. Ludemann, and B. Utecht. 1991. Elafin is a potent inhibitor of proteinase 3. Biochem. Biophys. Res. Commun. 174:6-10.

59. Wideow, O., J.-M. Schroder, H. Gregory, J.A. Young, and E. Christophers. 1990. Elafin: an elastase-specific inhibitor of human skin. J. Biol. Chem. 265:14791-14795.

60. Alonso, D., P. Starek, and C. Minick. 1977. Studies on the pathogenesis of atherosclerosis induced in rabbit cardiac allografts by the synergy of graft rejection and hypercholesterolemia. Am. J. Pathol. 87:415-442.

61. Foegh, M.L., B. Khirabadi, E. Chambers, and P. Ramwell. 1989. Peptide inhibition of accelerated transplant atherosclerosis. Transplant. Proc. 21:36743676.

62. Foegh, M.L. 1993. Accelerated cardiac transplant atherosclerosis/chronic rejection in rabbits: inhibition by angiopeptin. Transplant. Proc. 25:2095-2097.

63. Eich, D., J. Nestler, D. Johnson, G. Dworkin, D. Ko, A. Wechsler, and M. Hess. 1993. Inhibition of accelerated coronary atherosclerosis with dehydroepiandrosterone in the heterotopic rabbit model of cardiac transplantation. Circulation. 87:261-269.

64. Hornebeck, W., J.C. Derouette, and L. Robert. 1975. Isolation, purification and properties of aortic elastase. FEBS Lett. 58:66-70.

65. LaBourene, J., J. Coles, D. Johnson, A. Mehra, F. Keeley, and M. Rabinovitch. 1990. Alterations in elastin and collagen related to the mechanism of progressive pulmonary venous obstruction in a piglet model. A hemodynamic, ultrastructural, and biochemical study. Circ. Res. 66:438-456.

66. Takahashi, S., S. Seifter, and F. Yang. 1973. A new radioactive assay for enzymes with elastolytic activity using reduced tritiated elastin: the effect of sodium dodecylsulfate on elastolysis. Biochem. Biophys. Acta. 327:138-145.

67. Damle, N., and A. Arufo. 1991. Vascular cell adhesion molecule 1 induces $\mathrm{T}$ cell antigen receptor-dependent activation of $\mathrm{CD}^{+}$lymphocytes. Immunology. 88:6403-5407.

68. Hunt, S. 1987. Preparation of Lymphocytes and Accessory Cells. Lymphocytes: A Practical Approach. IRL Press. Oxford.

69. Banda, M.J., H.F. Dovey, and Z. Werb. 1981. Elastinolytic enzymes. In Methods for Studying Mononuclear Phagocytes. D.O. Adams, P.J. Edelson, and H. Koren, editors. Academic Press. New York. 1981:603-618.

70. Cowan, B., S. Molossi, C. Coulber, and M. Rabinovitch. 1994. Interleukin (IL)-1 $\beta$ stimulated fibronectin synthesis in coronary smooth muscle cells requires endogenous vascular elastase activity. Mol. Biol. Cell. 5(Suppl.):429a.

71. Boudreau, N., E. Turley, and M. Rabinovitch. 1991. Fibronectin, hyaluronan and a hyaluronan binding protein contribute to increased ductus arteriosus smooth muscle cell migration. Dev. Biol. 143:235-247.

72. Tanaka, H., S.J. Swanson, G. Sukhova, F.J. Schoen, and P. Libby. 1995. Early proliferation of medial smooth muscle cells in coronary arteries of rabbit cardiac allografts during immunosuppression with cyclosporine A. Transplant. Proc. 27:2062-2065.

73. Clowes, A.W., and M.J. Karnowsky. 1977. Suppression by heparin of smooth muscle cell proliferation in injured arteries. Nature (Lond.). 265:625-626.

74. Clowes, A.W., and M.M. Clowes. 1986. Kinetics of cellular proliferation after arterial injury. IV. Heparin inhibits rat smooth muscle mitogenesis and migration. Circ. Res. 58:839-845.

75. Clowes, A.W., M.M. Clowes, and M.A. Reidy. 1986. Kinetics of cellular proliferation after arterial injury. III. Endothelial and smooth muscle cell growth in chronically denuded vessels. Lab. Invest. 54:295-303.

76. Clowes, A.W., M.M. Clowes, Y.P.T. Au, M.A. Reidy, and D. Belin. 1990. Smooth muscle cells express urokinase during mitogenesis and tissue-type plasminogen activator during migration in injured rat carotid artery. Circ. Res. 67:61-67.

77. Romanic, A.M., and J.A. Madri. 1994. The induction of 72-kD gelatinase in T cells upon adhesion to endothelial cells is VCAM-1 dependent. J. Cell Biol. 125:1165-1178.

78. Foegh, M., B. Khirabadi, E. Chambers, S. Amamoo, and P. Ramwell. 1989. Inhibition of coronary artery transplant atherosclerosis in rabbits with angiopeptin, an octapeptide. Atherosclerosis. 78:229-236.

79. Salomon, R., C. Hughes, F. Schoen, D. Payne, J. Pober, and P. Libby. 1991. Human coronary transplantation-associated arteriosclerosis. Am. J. Pathol. 138:791-798.

80. Johnson, M. 1992. Transplant coronary disease: nonimmunologic risk factors. J. Heart Lung Transplant. 11:S124-S132.

81. Hornebeck, W., J.J. Adnett, and L. Robert. 1978. Age dependent variation of elastin and elastase in aorta and human breast cancers. Exp. Gerontol. 13:283-298.

82. O'Brien, J., and W. Regan. 1991. A study of elastic tissue and actinic radiation in "aging," temporal arteritis, polymyalgia rheumatica, and atherosclerosis: the actinic storm in the modern world. J. Am. Acad. Dermatol. 24:765-776.

83. Sukhova, G., D. Simon, H. Chapman, and P. Libby. 1995. Cytokines regulate the expression by vascular smooth muscle cells of cathepsin $\mathrm{S}$, an elastase found in human atheroma. Circulation. 92(Suppl.):I-169.

84. Todorovich-Hunter, L., H. Dodo, C. Ye, L. McCready, F. Keeley, and M. Rabinovitch. 1992. Increased pulmonary artery elastolytic activity in rats with monocrotaline-induced progressive hypertensive pulmonary vascular disease compared with infant rats with nonprogressive disease. Am. Rev. Respir. Dis. 146:213-223.

85. Ye, C., and M. Rabinovitch. 1991. Inhibition of elastolysis by SC-37689 reduces development and progression of monocrotaline pulmonary hypertension. Am. J. Physiol. 261:H1255-H1267.

86. Maruyama, K., C. Ye, M. Woo, H. Venkatacharya, L. Lines, M. Silver, and M. Rabinovitch. 1991. Chronic hypoxic pulmonary hypertension in rats and increased elastolytic activity. Am. J. Physiol. 261:H1716-H1726.

87. Shemie, S., and M. Rabinovitch. 1993. The effect of alpha-1 antitrypsin inhibition of the early elastase release on the pathophysiology of progressive pulmonary hypertension. Am. Rev. Respir. Dis. 147:495a. (Abstr.).

88. Oho, S., E. Koo, A. Gotlieb, and M. Rabinovitch. 1995. Increased elastolytic activity associated with intimal proliferation in the porcine aortic organ culture. FASEB J. 7:491a (Abstr.).

89. Hudig, D., G.R. Ewoldt, and S.L. Woodard. 1993. Proteases and lymphocyte cytotoxic killing mechanisms. Curr. Opin. Immunol. 5:90-96.

90. Tschopp, J., and C.V. Jongeneel. 1988. Cytotoxic T lymphocyte mediated cytolysis. Biochemistry. 27:2641-2646.

91. Simon, M.M., U. Fruth, H.G. Simon, and M.D. Kramer. 1986. A specific serine proteinase is inducible in $\mathrm{Lyt}-2^{+}, \mathrm{L}_{3} \mathrm{~T}^{-}$and $\mathrm{Lyt}-2^{-}, \mathrm{L} 3 \mathrm{~T} 4^{+} \mathrm{T}$ cells in vitro but is mainly associated with Lyt-2 ${ }^{+}, \mathrm{L} 3 \mathrm{~T} 4^{-}$effector cells in vivo. Eur. $J$. Immunol. 16:1559-1568.

92. Senior, R.M., E.J. Campbell, J.A. Landis, F.R. Cox, C. Khun, and H.S. Koren. 1982. Elastase of U-937 monocytelike cells. Comparisons with elastases derived from human monocytes and neutrophils and murine macrophagelike cells. J. Clin. Invest. 69:384-393.

93. Senior, R.M., and E.J. Campbell. 1984. Cathepsin G in human mononuclear phagocytes: comparisons between monocytes and U937 monocyte-like cells. J. Immunol. 132:2547-2551.

94. Tsunemi, M., H. Kato, Y. Nishiuchi, S.-I. Kumagaye, and S. Sakakibara. 1992. Synthesis and structure-activity relationships of elafin, an elastase-specific inhibitor. Biochem. Biophys. Res. Commun. 185:967-973.

95. Sallenave, J.-M., J. Shulmann, J. Crossley, M. Jordana, and J. Gauldie. 1994. Regulation of secretory leukocyte proteinase inhibitor (SLPI) and elastase-specific inhibitor (ESI/Elafin) in human airway epithelial cells by cytokines and neutrophilic enzymes. Am. J. Respir. Cell Mol. Biol. 11:733-741.

96. Crinnion, J.N., S. Homer-Vanniasinkam, R. Hatton, S.M. Parkin, and M.J. Gough. 1994. Role of neutrophil depletion and elastase inhibition in modifying skeletal muscle reperfusion injury. Cardiovasc. Surg. 2:749-753.

97. Nara, K., S. Ito, Y. Suzuki, M. Ghoneim, S. Tachibana, and S. Hirose. 1994. Elastase inhibitor elafin is a new type of proteinase inhibitor which has a transglutaminase-mediated anchoring sequence termed "cementoin." J. Biochem. 115:441-448.

98. Zhang, M., Z. Zou, N. Maass, and R. Sager. 1995. Differential expression of elafin in human normal mammary epithelial cells and carcinomas is regulated at the transcriptional level. Cancer Res. 55:2537-2541.

99. Billingham, M.E., N.R.B. Cary, M.E. Hammond, J. Kemnitz, C. Marboe, H.A. McAllister, D.C. Snovar, G.L. Winters, and A. Zerbe. 1990. A working formulation for the standardization of nomenclature in the diagnosis of heart and lung rejection: heart rejection study group. J. Heart Transplant. 9: 587-593.

100. Billingham, M. 1979. Some recent advances in cardiac pathology. Hum. Pathol. 10:367-386. 
101. Tyagi, S.C., A. Ratajska, and K.T. Weber. 1993. Myocardial matrix metalloproteinase(s): localization and activation. Mol. Cell. Biochem. 126:49-59.

102. Jones, P.A., and Z. Werb. 1980. Degradation of connective tissue matrices by macrophages. II. Influence of matrix composition on proteolysis of glycoproteins, elastin, and collagen by macrophages in culture. J. Exp. Med. 152:1527-1536.

103. Fine, R., M.E. Campbell, and J.F. Collins. 1984. Elastolytic activity of peripheral blood monocytes. Connect. Tissue Res. 13:27-35.

104. Griffiths, G.M., R. Namikawa, C. Mueller, C.C. Liu, J.D. Young, M. Billingham, and I. Weissmam. 1991. Granzyme A and perforin as markers for rejection in cardiac transplantation. Eur. J. Immunol. 21:687-693.

105. Clement, M.V., P. Haddad, A. Soulie, C. Benvenuti, M.G. Lichtenheld, E.R. Podack, N. Sigaux, and M. Sasportes. 1991. Perforin and granzyme B as markers for acute rejection in heart transplantation. Int. Immunol. 3:1175-1181.

106. Clement, M.V., A. Soulie, S. Legros-Maida, J. Guillet, E. Gluckman, N. Sigaux, and M. Sasportes. 1991. Perforin and granzyme B: predictive markers for acute GVHD or cardiac rejection after bone marrow or heart transplantation. Nouv. Rev. Fr. Hematol. 33:465-470.

107. Hudig, D., D. Redelman, and L.L. Minning. 1984. The requirement for proteinase activity for human lymphocyte-mediated natural cytotoxicity (NK): evidence that the proteinase is serine dependent and has aromatic amino acid specificity of cleavage. J. Immunol. 133:2647-2654.

108. Ruers, T.J.M., B. Schutte, C.J. van der Linden, and W.A. Buurman 1990. Cellular proliferation at the site of organ allografts and the influence of immunosuppressive therapy. Transplantation (Baltimore). 50:568-572. 